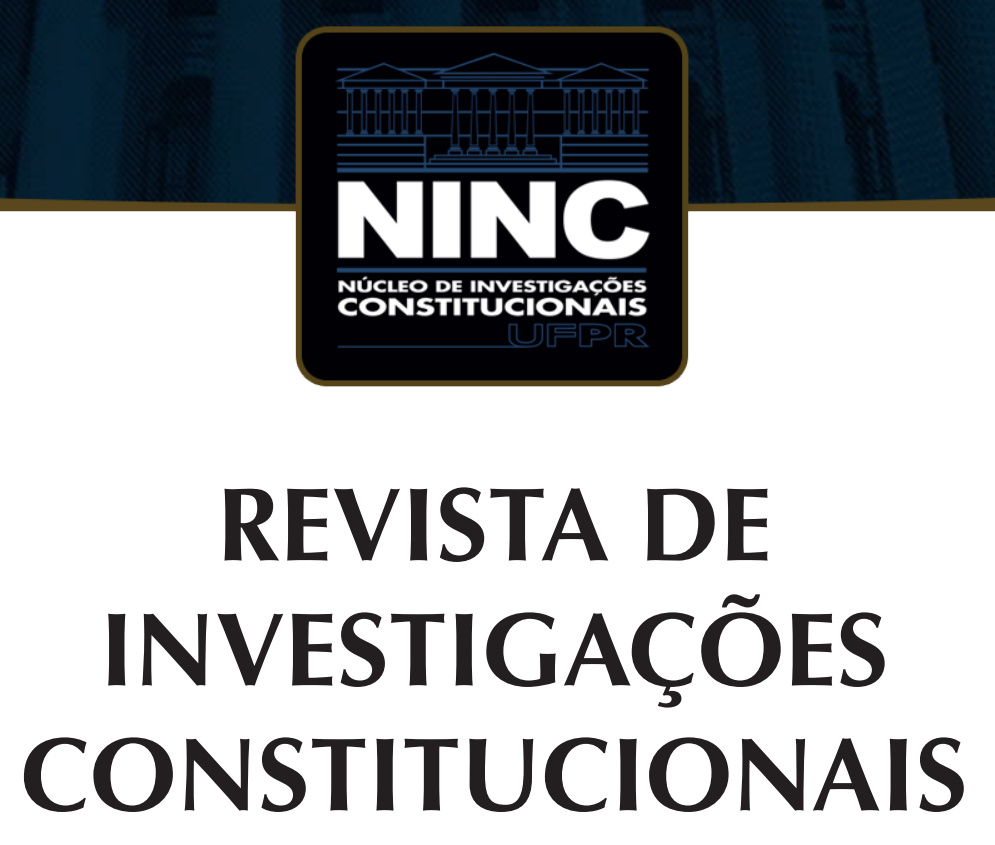

JOURNAL OF CONSTITUTIONAL RESEARCH

vol. 6 | n. 2 | maio/agosto 2019 | ISSN 2359-5639 | Periodicidade quadrimestral Curitiba | Núcleo de Investigações Constitucionais da UFPR | www.ninc.com.br 


\title{
El nuevo Pilar Europeo de Derechos Sociales: ¿hacia un fortalecimiento real de la dimensión social de la Unión Europea?
}

\author{
The new European Pillar of Social Rights: towards a real \\ strengthening of the social dimension of the European Union?
}

\author{
LUCÍA CASADO CASADO ${ }^{1, *}$ \\ 'Universidad Rovira i Virgili (España)
}

lucia.casado@urv.cat

http://orcid.org/0000-0001-5603-3264

Recebido/Received: 26.09 .2018 / September $26^{\text {th }}, 2018$

Aprovado/Approved: 18.11.2019/ November $18^{\text {th }}, 2019$

\section{Resumen}

Este trabajo se centra en el estudio del Pilar Europeo de Derechos Sociales, aprobado recientemente en el seno de la Unión Europea. Con esta finalidad, tras una breve introducción que sitúa el objeto y el contexto del trabajo, procede a analizar, en primer lugar, el proceso de gestación de este Pilar, desde sus primeros pasos, en septiembre de 2015 , hasta su aprobación mediante una Recomendación de la Comisión en abril de 2017 y su proclamación, conjuntamente por el Parlamento Europeo, el Consejo y la Comisión, en noviembre de 2017. En segundo lugar, examina en profundidad las razones que subyacen a la aprobación del Pilar Europeo de Derechos Sociales, sus objetivos y su contenido, destacando en especial sus principales aportaciones y novedades y sus limitaciones. En tercer lugar, repasa las principales acciones emprendidas a nivel europeo tras la aprobación del Pilar, con el fin de hacer efectivas sus previsiones. Por
Abstract

This study focuses on the European Pillar of Social Rights which was recently approved by the European Union. The study begins with a brief introduction describing the stu$d y$ 's aim and context, before proceeding to analyse, first of all, the process that brought the Pillar into being, from the initial steps taken in September 2015 to its approval by means of a Commission Recommendation in April 2017 and the joint proclamation by the European Parliament, Council and Commission in November 2017. Secondly, the study will then examine in depth the reasons underlying the approval of the European Pillar of Social Rights, its objectives and content, paying particular attention to its principal contributions, novelties and limitations. Thirdly, the study will review the principal actions taken at European level to put into effect the Pillar's provisions since it was approved. Finally, in the light of the data provided, the study will conclude with some final considerations regarding the

Como citar esse artigo/How to cite this article: CASADO CASADO, Lucía. El nuevo Pilar Europeo de Derechos Sociales: ¿hacia un fortalecimiento real de la dimensión social de la Unión Europea? Revista de Investigações Constitucionais, Curitiba, vol. 6 , n. 2, p. 375-404, maio/ago. 2019. DOI: 10.5380/rinc.v6i2.61813.

* Profesora Titular de Derecho Administrativo de la Universidad Rovira i Virgili (Tarragona, España). Doctora en Derecho por la Universidad Autónoma de Barcelona. Subdirectora del Centro de Estudios de Derecho Ambiental de Tarragona (CEDAT). Miembro de la Red Docente Eurolatinoamericana de Derecho Administrativo (REDOEDA), de la Asociación Española de Profesores de Derecho Administrativo (AEPDA) y del Observatorio de Políticas Ambientales (OPAM). E-mail: lucia.casado@urv.cat. 
último, el trabajo se cierra con unas consideraciones finales, en que, a la luz de los datos proporcionados, se realiza una valoración de este instrumento, de su potencialidad y de sus limitaciones, en el seno de la Unión Europea como vía para fortalecer su dimensión social.

Palabras clave: Pilar europeo de derechos sociales; derechos sociales; Unión Europea; política social; protección social. potential effectiveness and limitations of this instrument as a means of strengthening the social dimension of the European Union.

Keywords: European Pillar of Social Rights; social rights; European Union; social policy; social protection.

\section{SUMARIO}

1. Introducción; 2. Los orígenes del Pilar Europeo de Derechos Sociales. El camino seguido hasta su aprobación; 3. El Pilar Europeo de Derechos Sociales; 3.1. ¿Por qué aprobar un Pilar Europeo de Derechos Sociales?; 3.2. Objetivos; 3.3. Ámbito de aplicación; 3.4. Estructura y contenido; 3.5. Principales aportaciones; 3.6. Principales limitaciones; 4. Acciones posteriores a nivel europeo tras la aprobación del Pilar Europeo de Derechos Sociales; 5. Consideraciones finales; 6 . Referencias.

\section{INTRODUCCIÓN}

La Unión Europea cuenta con una política social ${ }^{1}$ y la dimensión social está bien presente en los Tratados Europeos ${ }^{2}$. Buena prueba de ello son las previsiones contenidas en el Tratado de la Unión Europea ${ }^{3}$ y en el Tratado de Funcionamiento de la Unión Europea ${ }^{4}$. Asimismo, existe un extenso acervo comunitario en este ámbito, habiéndose adoptado numerosas normas de derecho derivado que regulan las relaciones laborales (por ejemplo, en materia de seguridad y salud en el trabajo, ordenación del tiempo de trabajo, igualdad de trato entre hombres y mujeres, igualdad de trato en el empleo y la ocupación...). Igualmente, son relevantes las previsiones de índole social contenidas en la Carta de Derechos Fundamentales de la Unión Europea, que pertenece al derecho originario y tiene una fuerte impronta social, garantizando numerosos derechos de

\footnotetext{
Sobre la política social de la Unión Europea, vid. GÓMEZ, Marta Ortega. La política social, el empleo y otras normas sociales de la Unión Europea. En: GÓMEZ, Marta (ed.). Las políticas de la Unión Europea en el siglo XXI. Barcelona: Bosch, 2017, p. 375-405.

2 Sobre la evolución de la política social de la Unión Europea, vid. SANZ, Rosario Pedrosa. El desarrollo histórico de la Política Social de la Unión Europea y su estado actual. Estudios de Economía aplicada, Valladolid, v. 27-3, 2009, p. 613-638.

3 Vid. el artículo 3 de este Tratado, que atribuye a la Unión Europea diversos objetivos en el ámbito social, entre los que se incluyen la promoción del bienestar, la lucha contra la exclusión social y la discriminación; el fomento de la justicia y la protección sociales, la igualdad entre hombres y mujeres, la solidaridad entre las generaciones y la protección de los derechos del niño; y el fomento de la cohesión económica, social y territorial y la solidaridad entre los Estados miembros.

4 Vid. los artículos 151 a 161 de este Tratado, que integran el Título X, titulado "Política Social", de la Parte Tercera, que sirven de base a la Unión Europea para la adopción de normas, dentro de sus competencias, en materia social.
} 
esta naturaleza ${ }^{5}$; y el impulso judicial dado a esta materia por el Tribunal de Justicia de la Unión Europea, cuya jurisprudencia se está convirtiendo en una herramienta decisiva y ha dado lugar a avances relevantes ${ }^{6}$.

Sin embargo, las competencias de la Unión Europea en materia social son muy limitadas. En efecto, la política social es una política compartida entre los Estados miembros y la Unión Europea ${ }^{7}$ y las prerrogativas de ésta son muy escasas en este ámbito, excluyéndose cualquier poder normativo en materia de empleo ${ }^{8}$. De acuerdo con el artículo 153 del Tratado de Funcionamiento de la Unión Europea, la competencia de la Unión es una mera competencia de apoyo y complemento a la actividad de los Estados miembros ${ }^{9}$, por lo que son éstos los principales responsables de definir sus políticas sociales y de empleo ${ }^{10}$. Además, también debe tenerse presente que, en el seno de la Unión, la adopción de medidas normativas sobre determinadas materias exige la unanimidad. Así sucede con los ámbitos relativos a la seguridad social y la protección social de los trabajadores; la protección de los trabajadores en caso de rescisión del contrato laboral; la representación y la defensa colectiva de los intereses de los trabajadores y de los empresarios, incluida la cogestión; y las condiciones de empleo de los nacionales de terceros países que residan legalmente en el territorio de la Unión ${ }^{11}$. De ahí las dificultades con las que se encuentra la Unión para intervenir en materia social.

5 GÓMEZ, Marta Ortega. La política social, el empleo y otras normas sociales de la Unión Europea. En: GÓMEZ, Marta Ortega (ed.). Las políticas de la Unión Europea en el siglo XXI. Barcelona: Bosch, 2017, p. 379.

6 Al respecto, vid. BROTO, José María Miranda. El derecho social de la Unión Europea en la encrucijada: entre la parálisis legislativa y el impulso judicial. Revista del Ministerio de Empleo y Seguridad Social, Madrid, $\mathrm{n}$. 127, 2017, p. 19-43.

7 Vid. el artículo 4.2.b) del Tratado de Funcionamiento de la Unión Europea.

8 En este sentido, GÓMEZ, Marta Ortega. La política social, el empleo y otras normas sociales de la Unión Europea. En: GÓMEZ, Marta Ortega (ed.). Las políticas de la Unión Europea en el siglo XXI. Barcelona: Bosch, 2017, p. 375.

9 El artículo 153 del TFUE dispone que, para la consecución de los objetivos del artículo 151, la Unión apoyará y completará la acción de los Estados miembros en los siguientes ámbitos: la mejora, en concreto, del entorno de trabajo, para proteger la salud y la seguridad de los trabajadores; las condiciones de trabajo; la seguridad social y la protección social de los trabajadores; la protección de los trabajadores en caso de rescisión del contrato laboral; la información y la consulta a los trabajadores; la representación y la defensa colectiva de los intereses de los trabajadores y de los empresarios; las condiciones de empleo de los nacionales de terceros países que residan legalmente en el territorio de la Unión; la integración de las personas excluidas del mercado laboral; la igualdad entre hombres y mujeres por lo que respecta a las oportunidades en el mercado laboral y al trato en el trabajo; la lucha contra la exclusión social; y la modernización de los sistemas de protección social.

10 Además, como advierte GÓMEZ, Marta Ortega. La política social, el empleo y otras normas sociales de la Unión Europea. En: GÓMEZ, Marta Ortega (ed.). Las políticas de la Unión Europea en el siglo XXI. Barcelona: Bosch, 2017, p. 375, "Los Estados miembros de la Unión Europea nunca han pretendido crear una política social y de empleo a escala europea. No han tenido interés en posibilitar que la UE tenga un poder autónomo respecto de las relaciones empresario trabajador y en los aspectos que conciernen al empleo y al bienestar social, bienestar que, por otra parte, resulta indisociable de la marcha de la economía".

11 Vid. el artículo 153. 2 del Tratado de Funcionamiento de la Unión Europea. 
Asimismo, tanto la existencia de la política social europea como su contenido, el grado de intervención que debe tener o el papel a desempeñar siempre han suscitado grandes controversias y debates en el seno de la Unión ${ }^{12}$.

La preocupación por la dimensión social de la Unión Europea ha emergido con fuerza a raíz de la crisis económica suscitada a partir de 2008, que ha tenido un fuerte impacto social y ha significado la reducción y restricción de derechos sociales en muchos Estados miembros, y también el incremento del número de personas desempleadas, de las desigualdades económicas y sociales y de la pobreza. ${ }^{13}$ En definitiva, la crisis económica ha llevado a que la protección de los derechos sociales también entre en crisis, a causa de las limitaciones presupuestarias y de las políticas de austeridad impuestas por la Unión Europea en los últimos años ${ }^{14}$, que han obligado a muchos Estados miembros a tomar medidas para reducir el gasto público. $Y$ ello ha conllevado un general redimensionamiento del Estado del bienestar europeo ${ }^{15}$. Precisamente, como señala Marta Ortega, son el déficit en el plano de las competencias y la falta de poder de la UE en materia social los factores que explican "por qué la UE no ha sido capaz de adoptar medidas de carácter social capaces de paliar los efectos negativos de la crisis en las personas, principalmente, el desempleo y la pobreza"16.

Ante esta preocupante realidad social en el seno de la Unión Europea, emerge con fuerza la necesidad de potenciar y fortalecer su dimensión social y la conveniencia de situar las políticas sociales y laborales en un nivel adecuado, evitando que se vean únicamente como un complemento de las políticas económicas. Las instituciones europeas y, en particular, la Comisión Europea, afrontan este reto y están emprendiendo acciones a tal efecto. Fortalecer la dimensión social de la Unión Europea y mitigar los impactos de la crisis sobre las políticas sociales y sobre las personas constituye un reto al cual debe darse una respuesta eficaz. Potenciar la dimensión social de la Unión

\footnotetext{
12 Así lo señala SANZ, Rosario Pedrosa. El desarrollo histórico de la Política Social de la Unión Europea y su estado actual. Estudios de Economía aplicada, Valladolid, v. 27-3, 2009, p. 634.

13 CASADO CASADO, Lucía. Crisis económica y protección del medio ambiente. El impacto de la crisis sobre el Derecho ambiental en España. Revista de Direito Econômico e Socioambiental, Curitiba, v. 9, n. 1, p. 18-63, jan./abr. 2018.

14 Como advierte BISCHOFF, Gabrielle. El modelo social europeo y los derechos de los trabajadores: ¿por qué necesitamos un pilar europeo de derechos sociales? Temas para el debate, Madrid, n. 268, 2017, p. 29-30, "Las políticas de austeridad de la UE han dado lugar a un aumento de la pobreza y la desigualdad, dejando a toda una generación sin perspectivas".

15 En este sentido, GARDINI, Gianluca. Crisis económica y protección de los derechos sociales en Europa. Reflexiones desde el ordenamiento italiano. Revista de Estudios de la Administración Local y Autonómica. Nueva Época, Madrid, n. 9, 2018, p. 94, quien también advierte que "muchos países de la UE, con el fin de obtener el apoyo financiero de Europa, tuvieron que reducir drásticamente el nivel de protección de muchos derechos sociales".

16 GÓMEZ, Marta Ortega. La Unión Europea frente a los retos políticos, económicos y sociales de la crisis de la Eurozona. En: PÉREZ, Jordi Bonet; ESTAPÀ, Jaume Saura (eds.). El Derecho internacional de los derechos humanos en períodos de crisis. Madrid: Marcial Pons, 2013, p. 227.
} 
Europea, como afirma Eduardo Rojo, "es una necesidad vital si queremos poner en marcha mecanismos a escala europea que contribuyan a la salida de la crisis en todos los países, aunque la rapidez de la misma sea desigual ya que las diferencias actuales son muy importantes"17. Es en este contexto donde debemos situar la adopción del nuevo Pilar Europeo de Derechos Sociales, que centrará este trabajo y a cuyo análisis dedicamos las páginas siguientes.

\section{LOS ORÍGENES DEL PILAR EUROPEO DE DERECHOS SOCIALES: EL CAMINO SEGUIDO HASTA SU APROBACIÓN}

El Pilar Europeo de Derechos Sociales se ha gestado en menos de dos años ${ }^{18}$. El punto de partida y el inicio del proceso conducente a su aprobación debe situarse en 2015, en una propuesta presentada por el presidente de la Comisión Europea, Jean Claude Juncker ${ }^{19}$. Concretamente, el 9 de septiembre de dicho año, propuso, ante el Plenario del Parlamento Europeo, el establecimiento de un pilar mínimo de derechos sociales ${ }^{20}$, que debería completar lo ya hecho en el ámbito de la Unión Europea; e

17 TORRECILLA, Eduardo Rojo. La construcción de la dimensión social de la Unión Europea: muchos retos pendientes y muchas necesidades a las que responder. Anuario IET de Trabajo y Relaciones Laborales, Barcelona, v. 2, 2014, p. 119.

18 Para un análisis detallado del proceso de gestación del Pilar Europeo de Derechos Sociales, vid. PÉREZ, José Luis Monereo; BERNAT, Juan Antonio Fernández. El pilar europeo de los derechos sociales: un mecanismo insuficiente para garantizar la dimensión social. Diario La Ley, Madrid, n. 9001, de 15 de junio de 2017, p. 1-23; AMORÓS, Francisco Pérez. Los retos laborales de la UE en su $60^{\circ}$ aniversario: el Pilar Europeo de Derechos Sociales (1). Trabajo y Derecho, Madrid, n. 35, 2017, p. 4-13; y TORRECILLA, Eduardo Rojo. La construcción del Pilar Europeo de Derechos Sociales. De la Propuesta Juncker (9.9.2015) a la Recomendación de la Comisión Europea (26.4.2017). ¿Más Europa social o reordenación del marco normativo vigente? Revista Galega de Dereito Social, Santiago de Compostela, n. 3, 2017.

19 Esta iniciativa forma parte de la labor emprendida por la Comisión en pos de una unión económica y monetaria (UEM) más profunda y más justa, y también de su programa de trabajo para 2016. Así se pone de manifiesto en la Comunicación de la Comisión al Parlamento Europeo, al Consejo, al Comité Económico y Social Europeo y al Comité de las Regiones "Apertura de una consulta sobre un pilar europeo de derechos sociales" [COM (2016) 127 final, Estrasburgo, 8 de marzo de 2016], p. 2. Con anterioridad a la propuesta presentada por Jean Claude Juncker, es interesante la Comunicación de la Comisión al Parlamento Europeo y al Consejo "Reforzar la dimensión social de la Unión económica y monetaria" [COM (2013) 690 final, Bruselas, 2 de octubre de 2013], así como las iniciativas emprendidas por la Unión Europea en 2014 para reforzar la Unión Económica y Monetaria y en las que se constata que ésta debe atender a la dimensión social [vid., en particular, las orientaciones políticas para la próxima Comisión Europea, presentadas por el entonces candidato al cargo de Presidente de la Comisión Europea, Jean Claude Juncker, "Un nuevo comienzo para Europa: mi Agenda en materia de empleo, crecimiento, equidad y cambio deomcrático", en la sesión plenaria del Parlamento Europeo, el 15 de julio de 2014 (disponible en: http://europa.eu/rapid/press-release_SPEECH-14-546_es.htm -fecha de la última consulta: 18 de septiembre de 2018-)]. Vid. QUINTANA, Margarita Isabel Ramos. El pilar europeo de derechos sociales: ¿nos ponemos serios? Trabajo y Derecho, Madrid, n. 24, 2016, p. 2. En particular, sobre la comunicación de 2 de octubre de 2013, vid. TORRECILLA, Eduardo Rojo. La construcción de la dimensión social de la Unión Europea: muchos retos pendientes y muchas necesidades a las que responder. Anuario IET de Trabajo y Relaciones Laborales, Barcelona, v. 2, 2014, p. 123-126.

20 Téngase en cuenta que, como pone de manifiesto QUINTANA, Margarita Isabel Ramos. El "momento cumbre" del pilar europeo de derechos sociales. Trabajo y Derecho, Madrid, n. 37, 2018, p. 2, tres meses antes, el denominado "Informe de los cinco presidentes" ya había dado muestras de la convicción de emprender otro 
identificar los elementos fundamentales, comunes a todos, relativos a las condiciones de trabajo, a la salud y seguridad en el trabajo, a la igualdad de trato entre hombres y mujeres, a las situaciones de desempleo, y, de forma más general, a las condiciones sociales y al acceso a los sistemas de protección social. Debía desarrollarse, por tanto, "un pilar europeo de derechos sociales que tenga en cuenta las cambiantes realidades de las sociedades europeas y el mundo del trabajo y que pueda servir de guía para una convergencia renovada en la zona euro"21. Sin embargo, el anuncio se formuló de forma breve, sin concreción alguna que permitiera deducir los objetivos a alcanzar con el mismo ni su alcance institucional ${ }^{22}$. Posteriormente, Jean Claude Juncker insistió en esta idea en una intervención realizada el 29 de septiembre de 2015, en el decimotercer congreso de la Confederación Europea de Sindicatos. En su discurso, reivindicó la Europa social y las virtudes del diálogo social para avanzar en las respuestas a la crisis que puedan satisfacer a la mayor parte de la ciudadanía; denunció el incremento de las desigualdades en buena parte de los países europeos; y anunció que la Comisión presentaría, en la primavera de 2016, un pilar de derechos sociales mínimos que sería un punto de partida que no podría ser disminuido ${ }^{23}$.

Una vez lanzada la propuesta, los primeros pasos efectivos de su materialización vinieron de la mano de la Comisión, que, respondiendo a la petición realizada, abrió, en marzo de 2016, un proceso de consulta sobre un pilar europeo de derechos sociales ${ }^{24}$, con el fin de reflexionar sobre los derechos sociales existentes, las necesidades particulares de la zona euro y las reformas necesarias a todos los niveles, que debería darse

rumbo para afrontar los efectos sociales devastadores de la crisis del post-2008 que se apartara de la aplicación pura y dura de políticas de austeridad.

21 Vid. BROTO, José María Miranda. El derecho social de la Unión Europea en la encrucijada: entre la parálisis legislativa y el impulso judicial. Revista del Ministerio de Empleo y Seguridad Social, Madrid, n. 127, 2017, p. 26.

22 Así lo destaca QUINTANA, Margarita Isabel Ramos. El pilar europeo de derechos sociales: ¿nos ponemos serios? Trabajo y Derecho, Madrid, n. 24, 2016, p. 1.

23 Vid. el análisis detallado de la Propuesta formula por Jean Claude Juncker y de las reacciones suscitadas que realiza TORRECILLA, Eduardo Rojo. La construcción del Pilar Europeo de Derechos Sociales. De la Propuesta Juncker (9.9.2015) a la Recomendación de la Comisión Europea (26.4.2017). ¿Más Europa social o reordenación del marco normativo vigente? Revista Galega de Dereito Social, Santiago de Compostela, n. 3, 2017, p. 13-20.

24 Vid. la Comunicación de la Comisión al Parlamento Europeo, al Consejo, al Comité Económico y Social Europeo y al Comité de las Regiones "Apertura de una consulta sobre un pilar europeo de derechos sociales". COM (2016) 127 final, Estrasburgo, 8 de marzo de 2016. Vid. también el Anexo que acompaña a esta Comunicación ("Primer esbozo preliminar de un pilar europeo de derechos sociales"); y los dos documentos de trabajo de los servicios de la Comisión Europea que también lo acompañan, uno dedicado a describir las tendencias clave de la economía, el mercado de trabajo y la sociedad en las que se basa el pilar ("Principales tendencias económicas, laborales y sociales en las que se basa el pilar europeo de derechos sociales") y otro a recordar el acervo jurídico social a nivel de la Unión Europea ("Acervo social de la Unión Europea"). Vid. un análisis detallado de esta comunicación en QUINTANA, Margarita Isabel Ramos. El pilar europeo de derechos sociales: ¿nos ponemos serios? Trabajo y Derecho, Madrid, n. 24, 2016, p. 1-4; y TORRECILLA, Eduardo Rojo. La construcción del Pilar Europeo de Derechos Sociales. De la Propuesta Juncker (9.9.2015) a la Recomendación de la Comisión Europea (26.4.2017). ¿Más Europa social o reordenación del marco normativo vigente? Revista Galega de Dereito Social, Santiago de Compostela, n. 3, 2017, p. 21-34. 
por terminado, a más tardar, el 31 de diciembre de 2016, y servir de base para que la Comisión pudiera presentar una propuesta final relativa al pilar a principios de 2017. Los objetivos principales de este proceso de consulta fueron los tres siguientes ${ }^{25}$ : hacer una evaluación del acervo social vigente de la Unión Europea, para ayudar a determinar en qué medida los derechos existentes se ejercen en la práctica y siguen siendo pertinentes para los retos presentes y futuros, o si deberían plantearse nuevas maneras de promover esos derechos; reflexionar sobre las nuevas tendencias en el trabajo y en las sociedades por efecto de las tendencias demográficas, las nuevas tecnologías y otros factores relevantes para la vida laboral y las condiciones sociales; y recabar puntos de vista y recibir comentarios sobre el propio esbozo del Pilar Europeo de Derechos Sociales, con el fin de debatir su alcance y su contenido, así como su papel como parte de la dimensión social de la Unión Económica y Monetaria, con vistas a ultimar una propuesta relativa al Pilar a principios de 2017.

Fruto de este proceso de consulta, abierto a las instituciones de la Unión Europea, a las autoridades y parlamentos nacionales, sindicatos y patronales, ONGs, proveedores de servicios sociales, expertos del mundo académico y el público en general, se realizaron numerosas aportaciones a la Comunicación de la Comisión, de procedencia muy variada (doctrina científica, Organización Internacional del Trabajo, Comité de las Regiones, Consejo Económico y Social Europeo, Parlamento Europeo, Consejo de Europa, Ministros de empleo de varios países de la Unión Europea.... $)^{26}$. Como pone de manifiesto Margarita Isabel Ramos, este proceso llevado a cabo a lo largo de 2016 por parte de la Comisión, tras la apertura de la mencionada consulta, "supone la expresión de una voluntad política orientada a reforzar, de algún modo, los aspectos sociales que tan deteriorados y tan desatendidos han estado, precisamente cuando más falta hacía, esto es, en los años de mayor impacto social de la crisis"27. Las numerosas aportaciones realizadas fueron objeto de debate, el 23 de enero de 2017, en una Conferencia de alto nivel en Bruselas, con más de 600 personas participantes en representación de los Estados miembros, las instituciones comunitarias, los interlocutores sociales y las organizaciones de la sociedad civil, que sirvió para acabar de moldear los textos que finalmente serían aprobados ${ }^{28}$.

25 Vid. la Comunicación de la Comisión al Parlamento Europeo, al Consejo, al Comité Económico y Social Europeo y al Comité de las Regiones "Apertura de una consulta sobre un pilar europeo de derechos sociales" [COM (2016) 127 final, Estrasburgo, 8 de marzo de 2016], p. 10.

26 Vid. el análisis detallado de las principales aportaciones que realiza TORRECILLA, Eduardo Rojo. La construcción del Pilar Europeo de Derechos Sociales. De la Propuesta Juncker (9.9.2015) a la Recomendación de la Comisión Europea (26.4.2017). ¿Más Europa social o reordenación del marco normativo vigente? Revista Galega de Dereito Social, Santiago de Compostela, n. 3, 2017, p. 35-50.

27 QUINTANA, Margarita Isabel Ramos. El pilar europeo de derechos sociales: ¿nos ponemos serios? Trabajo y Derecho, Madrid, n. 24, 2016, p. 1.

28 En este sentido, TORRECILLA, Eduardo Rojo. La construcción del Pilar Europeo de Derechos Sociales. De la Propuesta Juncker (9.9.2015) a la Recomendación de la Comisión Europea (26.4.2017). ¿Más Europa social o 
El paso siguiente en este proceso fue la aprobación de la Recomendación (UE) 2017/761 de la Comisión ${ }^{29}$, de 26 de abril de $2017^{30}$, sobre el Pilar Europeo de Derechos Sociales, cuyo análisis en profundidad acometemos en el apartado siguiente ${ }^{31}$. En ella se consagran los principios y derechos esenciales que conforman este Pilar, con el fin de que sirvan "de guía para alcanzar resultados sociales y de empleo eficientes para responder a los desafíos actuales y futuros con el fin de satisfacer las necesidades esenciales de la población, así como garantizar una mejor regulación y aplicación de los derechos sociales ${ }^{\prime 32}$. Ahora bien, como puede fácilmente apreciarse, el texto aprobado adopta la forma de recomendación, por lo que carece de efectos vinculantes y no impone obligaciones de necesario cumplimiento a sus destinatarios, sino meras proposiciones de cumplimiento facultativo. Esta Comunicación va acompañada de dos documentos de los servicios técnicos de la Comisión, en los que se hace balance de los contenidos más relevantes de las aportaciones efectuadas a la Comunicación de 8 de marzo de 2016; y se distingue entre el marco normativo vigente, las propuestas de cambio que introduce el texto de la Recomendación sobre el Pilar Europeo de Derechos Sociales respecto a aquél, y de qué forma puede instrumentarse en la práctica por vía comunitaria o nacional de cada Estado miembro.

Una vez se hizo pública esta Recomendación, comenzaron los contactos entre las principales instituciones de la Unión para negociar un acuerdo al respecto ${ }^{33}$. Fue así como, finalmente, tras su aprobación por el Consejo de Empleo, Política Social, Sanidad y Consumidores, en su sesión de 23 de octubre de 2017, se procedió a la firma

reordenación del marco normativo vigente? Revista Galega de Dereito Social, Santiago de Compostela, n. 3, 2017, p. 51.

29 Nótese que la Comisión, en realidad, presenta el Pilar, en la misma fecha, con un doble formato jurídico: como Recomendación de la Comisión de 26 de abril de 2017, y como Propuesta de proclamación interinstitucional para que tenga el mayor apoyo político institucional posible. Vid. AMORÓS, Francisco Pérez. Los retos laborales de la UE en su $60^{\circ}$ aniversario: el Pilar Europeo de Derechos Sociales (1). Trabajo y Derecho, Madrid, n. 35, 2017, p. 11.

30 Con anterioridad, el Parlamento Europeo también se había pronunciado en favor de un Pilar Europeo de Derechos Sociales sólido con el fin de reforzar los derechos sociales, ejercer un efecto positivo en la vida de las personas y apoyar la construcción europea del Siglo XXI. Vid. su Resolución de 19 de enero de 2017, sobre un Pilar Europeo de Derechos Sociales. Disponible en: <http://www.europarl.europa.eu/sides/getDoc.do?pubRef=-//EP//TEXT+TA+P8-TA-2017-0010+0+DOC+XML+V0//ES> Fecha de la última consulta: 19 set. 2018.

31 En opinión de TORRECILLA, Eduardo Rojo. La construcción del Pilar Europeo de Derechos Sociales. De la Propuesta Juncker (9.9.2015) a la Recomendación de la Comisión Europea (26.4.2017). ¿Más Europa social o reordenación del marco normativo vigente? Revista Galega de Dereito Social, Santiago de Compostela, n. 3, 2017, p. 61-62, la Recomendación presentada por la Comisión no difiere de las líneas maestras o ejes centrales de la Comunicación de 8 de marzo de 2016, si bien "cabe destacar que se han tenido en cuenta algunas aportaciones recibidas y que se ha tratado, tal como se explica con detalle en un documento elaborado por los servicios técnicos de la CE, de "aportar nuevos elementos al acervo existente" en la política social de que dispone la UE".

32 Recomendación (UE) 2017/761 de la Comisión, de 26 de abril de 2017, considerando $12^{\circ}$.

33 Vid. GALLARDO, Alfredo Romero. La discapacidad y el nuevo Pilar Europeo de Derechos Sociales. Siglo Cero, Salamanca, v. 49 (2), n. 266, 2018, p. 107. 
y proclamación interinstitucional del texto del Pilar Europeo de Derechos Sociales que figura en aquella Recomendación, de manera conjunta por el Parlamento Europeo, el Consejo y la Comisión, en la Cumbre social en favor del empleo justo y el crecimiento, celebrada en Gotemburgo el 17 de noviembre de 2017, a través de una declaración interinstitucional sin valor jurídico vinculante ${ }^{34}$. De este modo, se consigue el respaldo del Pilar al más alto nivel.

\section{EL PILAR EUROPEO DE DERECHOS SOCIALES}

Una vez descrito su proceso de gestación, a continuación, entramos a analizar detalladamente el Pilar Europeo de Derechos Sociales ${ }^{35}$. En particular, haremos referencia a las razones subyacentes a su aprobación; a sus objetivos; a su ámbito de aplicación; a su estructura y contenido; y a sus principales aportaciones y limitaciones.

\section{1. ¿Por qué aprobar un Pilar Europeo de Derechos Sociales?}

Antes de entrar a analizar el papel, estructura, contenido, alcance y naturaleza del Pilar Europeo de Derechos Sociales, conviene plantearnos el porqué de su aprobación ${ }^{36}$. Sólo así podremos comprender en sus justos términos este instrumento y sus implicaciones.

Entre las razones que explican su aprobación ${ }^{37}$, puede citarse, en primer lugar, la convicción de la importancia de la perspectiva social en el proceso de integración europea y la búsqueda de una economía social de mercado altamente competitiva. Si bien es cierto que el proceso de construcción europea se ha centrado en la convergencia económica en torno a un mercado único, también ha dado lugar al desarrollo de un destacable acervo sociolaboral, de gran importancia, especialmente en el periodo de crisis económica, y que, como pone de relieve, Borja Suárez, "ha servido para amortiguar las consecuencias sociales de la caída de la actividad y el aumento del desempleo" y “ha actuado también como estabilizador automático de la economía para preservar

\footnotetext{
34 Puede consultarse la versión en español de este documento en el siguiente enlace: <https://ec.europa.eu/ commission/sites/beta-political/files/social-summit-european-pillar-social-rights-booklet_es.pdf $>$ Fecha de la última consulta: 18 sep. 2018.

35 La cobertura jurídica de este nuevo instrumento de impulso de la política social dentro de la Unión Europea encuentra apoyo en varios preceptos de los Tratados fundacionales. Al respecto, vid. QUINTANA, Margarita Isabel Ramos. El pilar europeo de derechos sociales: ¿nos ponemos serios? Trabajo y Derecho, Madrid, n. 24, 2016, p. 1-2.

36 Sobre las razones que fundamentan el Pilar Europeo de Derechos Sociales, vid. QUINTANA, Margarita Isabel Ramos. El Pilar Europeo de Derechos Sociales: la nueva dimensión social europea. Revista de Derecho Social, Albacete, n. 77, 2017, p. 28-30.

37 Sobre las principales razones que justifican su aprobación y los principales aspectos que la Comisión tuvo muy presentes al impulsar esta iniciativa política, vid. CORUJO, Borja Suárez. El Pilar Europeo de Derechos Sociales ¿El anhelado punto de inflexión? Agenda Pública, El Periódico, 19 de noviembre de 2017.
} 
la capacidad de consumo evitando un frenazo económico aún de mayor entidad"38. Por esta razón, como señala la Comisión Europea ${ }^{39}$ :

[...] el establecimiento y la profundización del mercado único europeo han ido de la mano con el desarrollo de un acervo jurídico en el ámbito social a nivel de la UE, para garantizar la igualdad de condiciones, limitar el riesgo de dumping social o de "carrera a la baja" y facilitar la integración económica y social. Esta es también la razón por la que, desde la década de los noventa, las consideraciones sociales y relativas al empleo han constituido un rasgo esencial del proceso de coordinación de la política económica en la UE, conocido ahora como Semestre Europeo. La base del pilar europeo de derechos sociales sigue esta lógica [...]

En segundo lugar, el Pilar Europeo de Derechos Sociales responde a una doble necesidad: superar la crisis con perspectiva de futuro y avanzar hacia una Unión económica y monetaria más profunda y más justa ${ }^{40}$. Para que la Unión Europea pueda impulsar la productividad, competir a escala mundial, reforzar la cohesión social y seguir mejorando el nivel de vida de los ciudadanos, es imprescindible conseguir unos mercados de trabajo y unos sistemas de bienestar que funcionen correctamente y sean justos ${ }^{41}$. Asimismo, la Comisión considera que la consagración de un pilar social contribuirá de forma decisiva a la consolidación de la Unión económica y monetaria, por lo que es imprescindible prestar mayor atención a los resultados en materia de empleo y en el ámbito social, como parte de un proceso más amplio de convergencia al alza hacia unas estructuras económicas de mayor capacidad de resistencia dentro de la zona del euro ${ }^{42}$. En definitiva, parece que la relegación del componente social es uno de los de-

38 CORUJO, Borja Suárez. El Pilar Europeo de Derechos Sociales ¿El anhelado punto de inflexión? Agenda Pública, El Periódico, 19 de noviembre de 2017.

39 Comunicación de la Comisión al Parlamento Europeo, al Consejo, al Comité Económico y Social Europeo y al Comité de las Regiones "Apertura de una consulta sobre un pilar europeo de derechos sociales". COM (2016) 127 final, Estrasburgo, 8 de marzo de 2016, p. 3.

40 Sobre la necesidad de una dimensión social para la Unión económica y monetaria, vid. FERNANDES, Sofia; MASLAUSKAITE, Kristina. Une dimensión sociale pour l'UEM: pourquoi et comment? Policy Paper, París, n. 98, 2013, p. 1-16.

41 Vid. Comunicación de la Comisión al Parlamento Europeo, al Consejo, al Comité Económico y Social Europeo y al Comité de las Regiones "Apertura de una consulta sobre un pilar europeo de derechos sociales". COM (2016) 127 final, Estrasburgo, 8 de marzo de 2016, p. 4.

42 Desde esta perspectiva, la Comisión pone de relieve que "No se trata solamente de un imperativo político o social; es también una necesidad económica: la experiencia de la última década y media ha puesto de manifiesto que la persistencia de desequilibrios en uno o varios Estados miembros puede poner en peligro la estabilidad de la zona del euro en su conjunto, y que la incapacidad para corregir esos desequilibrios puede dar lugar a divergencias aún más onerosas. Después de la crisis de 2007-2008, la zona del euro se hizo más heterogénea, con algunos países especialmente afectados, y reducir esta heterogeneidad lleva tiempo. De cara al futuro, es evidente que el éxito venidero de la zona del euro depende no poco de la eficacia de los mercados de trabajo y los sistemas de bienestar nacionales y de la capacidad de la economía para absorber las perturbaciones y adaptarse a ellas". Vid. Comunicación de la Comisión al Parlamento Europeo, al Consejo, al Comité Económico 
fectos originales de carácter estructural en el diseño del euro que explica las enormes dificultades y sacrificios que han debido afrontar algunos países, como Grecia ${ }^{43}$.

En tercer lugar, el Pilar Europeo de Derechos Sociales también apunta a la necesidad de articular las instituciones típicas de protección social y laboral a un entorno socieconómico distinto y a un contexto marcado por la transformación de las sociedades europeas (progresivo envejecimiento de la población, alargamiento de la esperanza de vida...) y del mundo del trabajo (digitalización de la economía, transformación de los sistemas de trabajo, superación de las características tradicionales de la relación laboral... $)^{44}$. Indudablemente, el alcance y la naturaleza de los retos a los que se enfrentan el mundo del trabajo y la sociedad en general han cambiado radicalmente en la actualidad, en comparación con el siglo XX, por lo que existen muchas tendencias nuevas o futuras a las que Europa tendrá que adaptarse. Desde esta perspectiva,

Los objetivos de la política social y su capacidad para cumplirlos están siendo sometidos a prueba de forma significativa, y la capacidad de Europa para conseguir unos mercados de trabajo y unos sistemas de bienestar que funcionen correctamente y sean justos resulta esencial para que pueda impulsar la productividad, competir a escala mundial, reforzar la cohesión social y seguir mejorando el nivel de vida de sus ciudadanos ${ }^{45}$.

Por ello, es necesario reformular las respuestas tradicionales o, al menos, adaptarlas a un entorno socioeconómico distinto. Y ello en un momento en que la Unión Europea se enfrenta a dos grandes retos: la profunda evolución de los mercados y de las sociedades humanas con la globalización derivada de los cambios tecnológicos, económicos y sociales acaecidos; y la superación definitiva de una prolongada crisis económica y financiera, que ha provocado y todavía está provocando efectos nocivos ${ }^{46}$.

Es en este contexto y bajo estas premisas donde debemos situar el Pilar Europeo de Derechos Sociales que, como pone de relieve Alfredo Romero, "aspira a ser la brújula orientadora hacia resultados sociales y de empleo eficientes que respondan a los desafíos presentes y venideros, en aras de cubrir las demandas y necesidades ciudadanas

\footnotetext{
y Social Europeo y al Comité de las Regiones "Apertura de una consulta sobre un pilar europeo de derechos sociales". COM (2016) 127 final, Estrasburgo, 8 de marzo de 2016, p. 5.

43 Así lo advierte CORUJO, Borja Suárez. El Pilar Europeo de Derechos Sociales ¿El anhelado punto de infle xión? Agenda Pública, El Periódico, 19 de noviembre de 2017.

44 Así lo pone de manifiesto CORUJO, Borja Suárez. El Pilar Europeo de Derechos Sociales ¿El anhelado punto de inflexión? Agenda Pública, El Periódico, 19 de noviembre de 2017.

45 Comunicación de la Comisión al Parlamento Europeo, al Consejo, al Comité Económico y Social Europeo y al Comité de las Regiones "Apertura de una consulta sobre un pilar europeo de derechos sociales". COM (2016) 127 final, Estrasburgo, 8 de marzo de 2016, p. 4.

46 GALLARDO, Alfredo Romero. La discapacidad y el nuevo Pilar Europeo de Derechos Sociales. Siglo Cero, Salamanca, v. 49 (2), n. 266, 2018, p. 107.
} 
más elementales, así como para asegurar una mejor regulación y aplicabilidad de sus derechos" ${ }^{\prime \prime 7}$.

\subsection{Objetivos}

El Pilar Europeo de Derechos Sociales establece principios y derechos esenciales en materia social. Su objetivo fundamental es "manifestar una serie de principios esenciales en apoyo de unos mercados de trabajo y unos sistemas de bienestar que funcionen correctamente y sean justos"48. Así, establece una serie de principios y derechos que deben servir como marco de referencia para la política social y de empleo a escala nacional y europea y, con ello, "servir de guía para alcanzar resultados sociales y de empleo eficientes para responder a los desafíos actuales y futuros con el fin de satisfacer las necesidades esenciales de la población, así como garantizar una mejor regulación y aplicación de los derechos sociales"49. Tal como se destaca en un documento de trabajo de los servicios de la Comisión ${ }^{50}$

Conjuntamente, estos principios y derechos establecen una agenda ambiciosa para un mejor funcionamiento de las economías, así como para que las sociedades sean más equitativas y tengan una mayor capacidad de adaptación. El objetivo es promover un proceso renovado de convergencia hacia unas mejores condiciones de vida y de trabajo en toda Europa. En este contexto, el pilar europeo de derechos sociales aspira a proporcionar derechos nuevos y más efectivos a los ciudadanos, hacer frente a los retos sociales que van surgiendo y al cambiante mundo laboral, teniendo en cuenta en especial los nuevos tipos de trabajo derivados de las nuevas tecnologías y la revolución digital. Estos principios y derechos abarcan los ámbitos del empleo, la protección social, la inclusión social, la educación y la igualdad de oportunidades.

El Pilar "expresa los principios y derechos esenciales para el buen y justo funcionamiento de los mercados laborales y de los sistemas de bienestar de la Europa del siglo XXI" y reafirma "algunos de los derechos del acervo de la Unión y añade nuevos principios que abordan los desafíos derivados de los cambios económicos, tecnológicos

47 GALLARDO, Alfredo Romero. La discapacidad y el nuevo Pilar Europeo de Derechos Sociales. Siglo Cero, Salamanca, v. 49 (2), n. 266, 2018, p. 107.

48 Comunicación de la Comisión al Parlamento Europeo, al Consejo, al Comité Económico y Social Europeo y al Comité de las Regiones "Apertura de una consulta sobre un pilar europeo de derechos sociales". COM (2016) 127 final, Estrasburgo, 8 de marzo de 2016, p. 7.

49 Considerando $12^{\circ}$ de la Recomendación (UE) 2017/761 de la Comisión.

50 Vid. el Documento de trabajo de los servicios de la Comisión que acompaña a la Comunicación de la Comisión al Parlamento Europeo, al Consejo, al Comité Económico y Social Europeo y al Comité Europeo de las Regiones "Establecimiento de un pilar europeo de derechos sociales" [SWD (2017) 201 final, Bruselas, 26 de abril de 2017. Disponible en: <https://eur-lex.europa.eu/legal-content/ES/TXT/HTML/?uri=CELEX:52017SC0201\&from=EN>. Fecha de la última consulta: 18 sep. 2018. 
y sociales" ${ }^{\prime 1}$. Para ello, "se basará en el acervo social existente a nivel de la UE ${ }^{52}$, al que complementará, y los principios que contiene abordarán de manera específica las necesidades y los retos que afronta la zona del euro"53. En efecto, se inspira directamente en la variedad de las prácticas en toda Europa y se basa en el acervo legal existente en la Unión Europea y a escala internacional.

En definitiva, el Pilar Europeo de Derechos Sociales persigue erigirse en una guía para la mejora de las políticas sociales y de empleo en la Unión Europea y los Estados miembros, con el objeto de reforzar la dimensión social de la Unión y prepararla para la digitalización y la globalización. Una vez instaurado, "debería convertirse en un marco de referencia para analizar los resultados de los Estados miembros participantes en los ámbitos social y del empleo, para impulsar reformas a nivel nacional y, más concretamente, para servir de guía con vistas a una convergencia renovada en la zona del euro" ${ }^{\prime 54}$.

\section{3. Ámbito de aplicación}

En cuanto a su ámbito de aplicación, por una parte, debe tenerse presente que el Pilar Europeo de Derechos Sociales está principalmente concebido para la zona del euro ${ }^{55}$, aunque es aplicable a todos los Estados miembros que deseen formar parte de

51 Considerando $14^{\circ}$ de la Recomendación (UE) 2017/761 de la Comisión.

52 El Pilar Europeo de Derechos Sociales se basa en el corpus jurídico existente tanto en el contexto de la UE como en el ámbito internacional. En concreto, se basa en la Carta Comunitaria de los Derechos Sociales Fundamentales de los Trabajadores 1989, la Carta Social Europea de 1961, la Carta Social Europea en su versión revisada de 1996 y el Código Europeo de la Seguridad Social del Consejo de Europa. Los principios tienen en cuenta también los correspondientes convenios, recomendaciones y protocolos asociados de la Organización Internacional del Trabajo (OIT), así como la Convención de las Naciones Unidas sobre los derechos de las personas con discapacidad. Por otra parte, también tiene en cuenta el acervo social de la Unión Europea desarrollado en los últimos treinta años, por medio de nuevas disposiciones en los Tratados, la adopción de la Carta de los derechos fundamentales de la Unión Europea, la nueva legislación y la jurisprudencia del Tribunal de Justicia de la Unión Europea. Asimismo, tiene presente la adopción de los Objetivos de Desarrollo Sostenible de las Naciones Unidas para 2030, que ha proporcionado una nueva agenda para hacer frente a la erradicación de la pobreza, así como a las dimensiones económica, social, de solidaridad y de medio ambiente del desarrollo sostenible de forma equilibrada e integrada. Vid. el Documento de trabajo de los servicios de la Comisión que acompaña a la Comunicación de la Comisión al Parlamento Europeo, al Consejo, al Comité Económico y Social Europeo y al Comité Europeo de las Regiones "Establecimiento de un pilar europeo de derechos sociales".

53 Comunicación de la Comisión al Parlamento Europeo, al Consejo, al Comité Económico y Social Europeo y al Comité de las Regiones "Apertura de una consulta sobre un pilar europeo de derechos sociales". COM (2016) 127 final, Estrasburgo, 8 de marzo de 2016, p. 7.

54 Comunicación de la Comisión al Parlamento Europeo, al Consejo, al Comité Económico y Social Europeo y al Comité de las Regiones "Apertura de una consulta sobre un pilar europeo de derechos sociales". COM (2016) 127 final, Estrasburgo, 8 de marzo de 2016, p. 7.

55 PÉREZ, José Luis Monereo; BERNAT, Juan Antonio Fernández. El pilar europeo de los derechos sociales: un mecanismo insuficiente para garantizar la dimensión social. Diario La Ley, Madrid, n. 9001, de 15 de junio de 2017, p. 7, destaca el alcance limitado del Pilar, por cuanto con él "se pretende servir de guía con vistas a una convergencia renovada en la zona del euro". 
él, que podrán adherirse si lo desean ${ }^{56}$. De este modo, los principios que contiene abordarán de forma específica las necesidades y los retos a que debe hacer frente la zona del euro, con el fin de consolidar la Unión económica y monetaria, si bien ello no obsta a que pueda aplicarse a otros Estados miembros no integrados en la zona euro. De este modo, aunque territorialmente, en principio, queda referido exclusivamente a la zona del euro, al mismo tiempo, los países que no comparten la moneda europea pueden adherirse voluntariamente al Pilar e integrarlo en sus políticas, quedando por este cauce abierto a otros Estados no pertenecientes a la Unión económica y monetaria ${ }^{57}$. Se trata, por tanto, de una propuesta dirigida a todos los Estados miembros, de carácter abierto y dinámico, para adaptarse a situaciones diversas y a entornos socioeconómicos variables ${ }^{58}$.

Por otra, hay que tener en cuenta que los principios consagrados en este Pilar conciernen "a los ciudadanos de la Unión y a los nacionales de terceros países con residencia legal" ${ }^{\prime \prime}$, independientemente de su situación de empleo, así como a las autoridades públicas y a los interlocutores sociales ${ }^{60}$. Además, el Pilar utiliza un concepto amplio de "trabajador", de manera que cuando un principio hace referencia a los trabajadores "concierne a todas las personas con un empleo, independientemente de su situación laboral, y de la modalidad y duración del empleo"61.

\subsection{Estructura y contenido}

El Pilar Europeo de Derechos Sociales se estructura en tres capítulos diferentes, que responden a tres bloques temáticos (igualdad de oportunidades y de acceso al mercado de trabajo; condiciones de trabajo justas; y protección e inclusión social), en los que se recogen 20 grandes principios relacionados con los derechos sociales.

Estos principios tienen como punto de partida una serie de derechos ya inscritos en el acervo normativo de la Unión Europea (y también en el Derecho internacional) y presentan con mayor detalle las posibles maneras de hacerlos operativos, abordando

\footnotetext{
56 Vid. el Considerando $13^{\circ}$ de la Recomendación (UE) 2017/761 de la Comisión.

57 Vid. QUINTANA, Margarita Isabel Ramos. El Pilar Europeo de Derechos Sociales: la nueva dimensión social europea. Revista de Derecho Social, Albacete, n. 77, 2017, p. 30.

58 GALLARDO, Alfredo Romero. La discapacidad y el nuevo Pilar Europeo de Derechos Sociales. Siglo Cero, Salamanca, v. 49 (2), n. 266, 2018, p. 107-108.

59 Considerando $15^{\circ}$ de la Recomendación (UE) 2017/761 de la Comisión.

60 Vid. el Documento de trabajo de los servicios de la Comisión que acompaña a la Comunicación de la Comisión al Parlamento Europeo, al Consejo, al Comité Económico y Social Europeo y al Comité Europeo de las Regiones "Establecimiento de un pilar europeo de derechos sociales". En cuanto al alcance del Pilar, cabe destacar que se ha desechado la demanda del Consejo Económico y Social Europeo de que el Pilar tuviese en cuenta a los solicitantes de asilo y a los migrantes. Vid. PÉREZ, José Luis Monereo; BERNAT, Juan Antonio Fernández. El pilar europeo de los derechos sociales: un mecanismo insuficiente para garantizar la dimensión social. Diario La Ley, Madrid, n. 9001, de 15 de junio de 2017, p. 8, 9 y 11.

61 Considerando $15^{\circ}$ de la Recomendación (UE) 2017/761 de la Comisión.
} 
los desafíos surgidos con la crisis económica, los adelantos tecnológicos y los cambios sociales ${ }^{62}$. En realidad, el Pilar no supone la incorporación de más derechos o de nuevos derechos, ni en el ámbito europeo ni el ámbito interno de cada Estado miembro, sino que los complementa para tener en cuenta las nuevas realidades ${ }^{63}$.

En el Capítulo I, bajo el título "Igualdad de oportunidades y de acceso al mercado de trabajo", se recogen cuatro principios, relacionados con la educación, formación y aprendizaje permanente ${ }^{64}$; la igualdad de género ${ }^{65}$; la igualdad de oportunidades ${ }^{66}$; y el apoyo activo al empleo ${ }^{67}$ (incluidos, respectivamente, en los apartados 1, 2, 3 y 4 del Pilar).

El Capítulo II, titulado "Condiciones de trabajo justas", recoge, en los apartados 5 a 10, principios que guardan relación con las condiciones laborales, cuestión de enorme importancia para cualquier trabajador. En particular, se recogen principios relativos al empleo seguro y adaptable ${ }^{68}$; los salarios ${ }^{69}$; la información sobre las condiciones de

62 GALLARDO, Alfredo Romero. La discapacidad y el nuevo Pilar Europeo de Derechos Sociales. Siglo Cero, Salamanca, v. 49 (2), n. 266, 2018, p. 108.

63 Sobre esta cuestión vid. infra el apartado 3.6 de este trabajo.

64 En materia educativa, el apartado 1 recoge el derecho de toda persona "a una educación, formación y aprendizaje permanente inclusivos y de calidad, a fin de mantener y adquirir capacidades que les permitan participar plenamente en la sociedad y gestionar con éxito las transiciones en el mercado laboral".

65 En relación con la igualdad de género, el apartado 2 incluye el deber de garantizar y fomentar la igualdad de trato y oportunidades entre mujeres y hombres en todos los ámbitos, también en relación con la participación en el mercado laboral, las condiciones de trabajo y de empleo y la progresión de la carrera; y el derecho de las mujeres y los hombres "a la igualdad de retribución para un trabajo de igual valor".

66 El apartado 3 prevé que "Con independencia de su género, origen racial o étnico, religión o convicciones, discapacidad, edad u orientación sexual, toda persona tiene derecho a la igualdad de trato y de oportunidades en relación con el empleo, la protección social, la educación y el acceso a bienes y servicios a disposición del público. Deberá fomentarse la igualdad de oportunidades de los grupos infrarrepresentados".

67 En cuanto al apoyo activo para el empleo, se reconocen una serie de derechos a todas las personas (el derecho "a recibir asistencia personalizada y oportuna a fin de mejorar sus perspectivas de empleo o de trabajar por cuenta propia", que incluye el derecho "a recibir ayuda para la búsqueda de empleo, la formación y el reciclaje"; y "a la transferencia de la protección social" y "a la formación durante las transiciones profesionales"), a los jóvenes (el derecho "a educación continua, una formación como aprendices, un período de prácticas o una oferta de empleo de buena calidad en los cuatro meses siguientes a quedar desempleados o finalizar los estudios") y a las personas desempleadas (el derecho "a recibir una ayuda personalizada, continuada y adecuada" y, en el caso de los desempleados de larga duración, "a una evaluación individual detallada a más tardar a los dieciocho meses de desempleo"). Vid. el apartado 4.

68 El apartado 5 incluye diferentes previsiones relativa al empleo seguro y adaptable: el derecho de los trabajadores, con independencia del tipo y la duración de la relación laboral, "a un trato justo y equitativo en materia de condiciones de trabajo y el acceso a la protección social y a la formación" y el deber de fomentar "la transición hacia formas de empleo por tiempo indefinido"; el deber de garantizar, de conformidad con la legislación y los convenios colectivos, "la flexibilidad necesaria para que los empresarios puedan adaptarse con rapidez a los cambios en el contexto económico"; el deber de promover "formas innovadoras de trabajo que garanticen condiciones de trabajo de calidad" y de fomentar "el espíritu empresarial y el trabajo por cuenta propia" y de facilitar la movilidad profesional; y el deber de evitar "las relaciones laborales que den lugar a unas condiciones de trabajo precarias, en particular prohibiendo la utilización abusiva de contratos atípicos", debiendo tener los períodos de prueba una duración razonable.

69 En materia de salarios, de conformidad con el apartado 6, los trabajadores tienen derecho "a salarios justos que proporcionen un nivel de vida digno". Asimismo, se prevé que deberá garantizarse "un salario 
trabajo y la protección en caso de despido ${ }^{70}$; el diálogo social y la participación de los trabajadores ${ }^{71}$; el equilibrio entre la vida profesional y la vida privada ${ }^{72}$; y un entorno de trabajo saludable, seguro y adaptado y la protección de datos ${ }^{73}$. Se busca, en definitiva, establecer un equilibrio adecuado y fiable de derechos y obligaciones entre los trabajadores y los empleadores, así como entre flexibilidad y seguridad, de facilitar la creación de puestos de trabajo, la aceptación de estos y la adaptabilidad de las empresas y de promover el diálogo social ${ }^{74}$.

En el Capítulo III, con el título "Protección e inclusión"75, se incluyen, en los apartados 11 a 20, una serie de principios relativos a una protección social adecuada y sostenible, así como al acceso a servicios esenciales de alta calidad, a fin de garantizar a las personas una vida digna y la protección contra los riesgos. Todos ellos

mínimo adecuado que permita satisfacer las necesidades del trabajador y de su familia en función de las condiciones económicas y sociales, y que al mismo tiempo salvaguarde el acceso al empleo y los incentivos para buscar trabajo" y "evitarse la pobreza de los ocupados"; y que todos los salarios "deberán fijarse de manera transparente y predecible, con arreglo a las prácticas nacionales y respetando la autonomía de los interlocutores sociales".

70 Respecto de la información sobre las condiciones de trabajo y la protección en caso de despido, dos son las previsiones que se incluyen en el apartado 7: el derecho de los trabajadores "a ser informados por escrito al comienzo del empleo sobre sus derechos y obligaciones derivados de la relación laboral, incluso en período de prueba"; y el derecho, antes de proceder a un despido, de los trabajadores "a ser informados de los motivos de este y a que se les conceda un plazo razonable de preaviso", así como de "acceder a una resolución de litigios efectiva e imparcial" $y$, en caso de despido injustificado, el derecho "a reparación, incluida una indemnización adecuada".

71 En materia de diálogo social y participación de los trabajadores, el apartado 8 recoge el deber de consultar a los interlocutores sociales sobre "el diseño y la aplicación de políticas sociales, económicas y de empleo, de acuerdo con las prácticas nacionales", de animarlos "a que negocien y celebren convenios colectivos en asuntos de su incumbencia, respetando su autonomía y su derecho a la acción colectiva", así como el deber de fomentar "el apoyo para aumentar la capacidad de los interlocutores sociales para promover el diálogo social"; y el derecho de los trabajadores o sus representantes "a ser informados y consultados oportunamente sobre asuntos de interés para ellos, en particular sobre la transferencia, reestructuración y fusión de empresas y sobre despidos colectivos".

72 En relación con el equilibrio entre vida profesional y vida privada, el apartado 9 prevé que "Los padres y las personas con responsabilidades asistenciales tienen derecho a los permisos adecuados, a unas condiciones de trabajo flexibles y a servicios de asistencia. Las mujeres y los hombres deberán tener igualdad de acceso a permisos especiales para cumplir con sus responsabilidades asistenciales y deberá animárseles a utilizarlos de forma equilibrada".

73 En este ámbito, el Pilar incluye, en el apartado 10, el derecho de los trabajadores "a un elevado nivel de protección de la salud y la seguridad en el trabajo"; "a un entorno de trabajo adaptado a sus necesidades profesionales y que les permita prolongar su participación en el mercado laboral"; y "a la protección de sus datos personales en el contexto del empleo".

74 Vid. la Comunicación de la Comisión al Parlamento Europeo, a Consejo, al Comité Económico y Social Europeo y al Comité de las Regiones "Apertura de una consulta sobre un pilar europeo de derechos sociales", p. 8 [COM (2016) 127 final, Estrasburgo, 8 de marzo de 2016].

75 En opinión de PÉREZ, José Luis Monereo; BERNAT, Juan Antonio Fernández. El pilar europeo de los derechos sociales: un mecanismo insuficiente para garantizar la dimensión social. Diario La Ley, Madrid, n. 9001, de 15 de junio de 2017, p. 15, este Capítulo"es el más ambicioso de todos si se tiene en cuenta el conjunto de desafíos que esconde cada uno de sus principios en un contexto de restricciones presupuestarias y escaso crecimiento económico". 
abordan temas de gran relevancia social, por su permanente actualidad ${ }^{76}$. Concretamente, se recogen principios relativos a la asistencia y apoyo a los niños ${ }^{77}$; la protección social ${ }^{78}$; las prestaciones por desempleo ${ }^{79}$; la renta mínima ${ }^{80}$; las pensiones y prestaciones de vejez ${ }^{81}$; la sanidad ${ }^{82}$; la inclusión de las personas com discapacidad ${ }^{83}$; los cuidados de larga duración ${ }^{84}$; la vivienda y la asistencia para las personas sin hogar ${ }^{85}$; y el acceso a los servicios esenciales ${ }^{86}$.

76 GALLARDO, Alfredo Romero. La discapacidad y el nuevo Pilar Europeo de Derechos Sociales. Siglo Cero, Salamanca, v. 49 (2), n. 266, 2018, p. 110.

77 En materia de asistencia y apoyo a los niños, el apartado 11 incluye el derecho de los niños "a disfrutar de una educación y asistencia infantil asequibles y de buena calidad"; y "a la protección contra la pobreza". Asimismo, prevé que "Los niños procedentes de entornos desfavorecidos tienen derecho a medidas específicas destinadas a promover la igualdad de oportunidades".

78 Con relación a la protección social, el apartado 12 prevé que "Con independencia del tipo y la duración de su relación laboral, los trabajadores por cuenta ajena y, en condiciones comparables, los trabajadores por cuenta propia, tienen derecho a una protección social adecuada".

79 En cuanto a las prestaciones por desempleo, los desempleados "tienen derecho a ayudas adecuadas a la activación por parte de los servicios públicos de empleo para (re)integrarse en el mercado laboral y a prestaciones de desempleo adecuadas de duración razonable, en consonancia con sus propias contribuciones y los criterios de concesión nacionales". Eso sí, como cautela, se establece que estas prestaciones "no deberán desincentivar un retorno rápido al trabajo". Vid. el apartado 13.

80 El apartado 14 recoge el derecho de toda persona que carezca de recursos suficientes "a unas prestaciones de renta mínimas adecuadas que garanticen una vida digna a lo largo de todas las etapas de la vida, así como el acceso a bienes y servicios de capacitación". Asimismo, se prevé que, para las personas que pueden trabajar, "las prestaciones de renta mínima deben combinarse con incentivos a la (re)integración en el mercado laboral".

81 En materia de pensiones y prestaciones de vejez, el apartado 15 incluye el derecho de los trabajadores por cuenta ajena y por cuenta propia "a recibir una pensión de jubilación acorde a sus contribuciones que garantice una renta adecuada", imponiéndose que las mujeres y los hombres tengan las mismas oportunidades para adquirir derechos de pensión; y el derecho de toda persona en la vejez "a los recursos que garanticen una vida digna".

82 En relación con la sanidad, el apartado 16 hace referencia al derecho de toda persona "a un acceso oportuno a asistencia sanitaria asequible, de carácter preventivo y curativo y de buena calidad".

83 Para las personas con discapacidad, el apartado 17 recoge el derecho "a una ayuda a la renta que garantice una vida digna, a servicios que les permitan participar en el mercado laboral y en la sociedad y a un entorno de trabajo adaptado a sus necesidades". Vid. el comentario de este apartado que realizan GALLARDO, Alfredo Romero. La discapacidad y el nuevo Pilar Europeo de Derechos Sociales. Siglo Cero, Salamanca, v. 49 (2), n. 266, 2018, p. 110-111; y CORUJO, Borja Suaréz. Las personas con discapacidad en el Pilar Europeo de Derechos Sociales. En: RODRÍGUEZ, Erick Fernando Aristizábal (coord.). Las incapacidades laborales y la Seguridad Social en una sociedad en transformación: I Congreso Internacional y XIV Congreso Nacional de la Asociación Española de Salud y Seguridad Social. Murcia: Ediciones Laborum, 2017, p. 557-566.

84 Con relación a los cuidados de larga duración, el apartado 18 recoge el derecho de toda persona "a cuidados de larga duración asequibles y de buena calidad, en particular de asistencia a domicilio y servicios comunitarios".

85 En materia de vivienda, el apartado 19 incluye varias previsiones de interés: el deber de proporcionar a las personas necesitadas acceso a viviendas sociales o ayudas a la vivienda de buena calidad; el derecho de las personas vulnerables "a una asistencia y una protección adecuadas frente a un desalojo forzoso"; y el deber de facilitar a las personas sin hogar "un alojamiento y los servicios adecuados con el fin de promover su inclusión social".

86 El apartado 20 prevé que "Toda persona tiene derecho a acceder a servicios esenciales de alta calidad, incluidos el agua, el saneamiento, la energía, el transporte, los servicios financieros y las comunicaciones digitales. Deberá prestarse a las personas necesitadas apoyo para el acceso a estos servicios". 
Como puede comprobarse, estos veinte grandes principios se articulan en torno a dos grandes ejes: uno, relativo a las garantías de los trabajadores, del cual son exponente los Capítulos I y II, promueve la igualdad de oportunidades en el acceso al mercado de trabajo y la preservación de unas condiciones laborales justas para todos los trabajadores. El otro, incluido en el Capítulo III y de vocación más amplia en lo subjetivo, reivindica un nivel de protección social adecuado y sostenible en el seno de la Unión Europea. Sin duda, el reconocimiento de estos principios y derechos sociales es relevante, por su importancia económica y social, aunque es necesario que vaya acompañado de su efectividad práctica y no se quede en una simple plasmación formal en un texto.

\subsection{Principales aportaciones}

Sin perder de vista que el Pilar Europeo de Derechos Sociales está recogido en instrumentos carentes de fuerza jurídica vinculante ${ }^{87}$, cabe preguntarse qué aportaciones trae consigo su aprobación en el seno de la Unión Europea. Desde esta perspectiva, hay que destacar que su aprobación no supone, como ya hemos señalado, la incorporación de más derechos o nuevos derechos, ni altera el reparto competencial entre la Unión Europea y los Estados miembros en este ámbito.

Sin embargo, aunque no aumenta las competencias de la Unión ni hay modificaciones en el acervo jurídico europeo, no puede negarse la relevancia que tiene el reconocimiento de este conjunto de principios y derechos sociales esenciales y su plasmación en un texto en el ámbito de la Unión Europea, por cuanto se erige en un auténtico programa de principios. Aunque no incorpora más derechos, sí supone una reafirmación de los existentes, con algunas mejoras interpretativas. Por una parte, aporta una mayor visibilidad, mejora la comprensión y hace más explícitos para los ciudadanos y los diferentes agentes de todos los niveles los principios y derechos recogidos en las disposiciones vinculantes del Derecho de la Unión Europea ${ }^{88}$. Por otra, en algunos ámbitos concretos, el Pilar aporta nuevos elementos al acervo

\footnotetext{
87 A esta cuestión nos referimos con mayor detalle infra, en el apartado 3.6, de este trabajo.

88 Téngase en cuenta, además, que "ninguna de las disposiciones del pilar europeo de derechos sociales debe poder interpretarse como limitativa o lesiva de los derechos y principios reconocidos, en su respectivo ámbito de aplicación, por el Derecho de la Unión o por el Derecho internacional y por los convenios internacionales de los que son parte la Unión o los Estados miembros, incluida la Carta Social Europea, firmada en Turín el 18 de octubre de 1961, y los convenios y recomendaciones de la Organización Internacional del Trabajo" (considerando 16a de la Recomendación (UE) 2017/761).
} 


\section{existente $^{89}$ (por ejemplo, en materia de educación ${ }^{90}$, igualdad de género ${ }^{91}$, igualdad de oportunidades $^{92}$ y equilibrio entre vida profesional y vida privada ${ }^{93}$, por citar solo algu- nos ejemplos) ${ }^{94}$. Además, constituye un buen intento de sistematización y de visibiliza-}

89 Así se pone de manifiesto en el Documento de trabajo de los servicios de la Comisión que acompaña a la Comunicación de la Comisión al Parlamento Europeo, al Consejo, al Comité Económico y Social Europeo y al Comité Europeo de las Regiones "Establecimiento de un pilar europeo de derechos sociales".

90 En materia de educación, El Pilar establece un derecho general a la educación y a la formación a lo largo de toda la vida, que va más allá del artículo 14 de la Carta de los Derechos Fundamentales de la Unión Europea, ya que se centra en la calidad y el carácter inclusivo. Vid. el Documento de trabajo de los servicios de la Comisión que acompaña a la Comunicación de la Comisión al Parlamento Europeo, al Consejo, al Comité Económico y Social Europeo y al Comité Europeo de las Regiones "Establecimiento de un pilar europeo de derechos sociales".

91 En el ámbito de la igualdad de género, "El pilar hace énfasis sobre la necesidad de promover de forma proactiva la igualdad entre hombres y mujeres por medio de una actuación positiva en todos los ámbitos. Al extender la igualdad a todos los ámbitos, el pilar va más allá del acervo existente". Vid. el Documento de trabajo de los servicios de la Comisión que acompaña a la Comunicación de la Comisión al Parlamento Europeo, al Consejo, al Comité Económico y Social Europeo y al Comité Europeo de las Regiones "Establecimiento de un pilar europeo de derechos sociales".

92 En materia de igualdad de oportunidades, el Pilar "va en parte más allá del acervo actual al ampliar la protección contra la discriminación por motivo de religión o credo, discapacidad, edad y orientación sexual a los ámbitos de la protección social, incluidas la seguridad social y la sanidad, la educación y el acceso a los bienes y servicios disponibles para el público. El pilar también amplía la prohibición de discriminación basada en el género al ámbito de la educación, no incluido en el actual acervo". Vid. el Documento de trabajo de los servicios de la Comisión que acompaña a la Comunicación de la Comisión al Parlamento Europeo, al Consejo, al Comité Económico y Social Europeo y al Comité Europeo de las Regiones "Establecimiento de un pilar europeo de derechos sociales".

93 En relación con el equilibrio entre vida profesional y vida privada, el Pilar "destaca la importancia de la conciliación de vida familiar y vida profesional para todas las personas que tienen responsabilidades asistenciales y otorga derechos que son fundamentales para conseguir la conciliación en el actual contexto de trabajo, como es el derecho de acceso a los cuidados infantiles y a los cuidados de larga duración. El principio va más allá del actual acervo al establecer derechos para todas las personas con responsabilidades asistenciales que tiene un empleo. Por lo tanto, también se aplicará a las personas que tiene un empleo que no son padres, pero que por ejemplo puede que cuiden de personas de edad avanzada o miembros de su familia con una discapacidad". Además, "el pilar confiere el derecho a condiciones laborales flexibles, como el trabajo a distancia, la adaptación de los horarios de trabajo o pasar de una jornada completa a una jornada a tiempo parcial. En la actualidad ese derecho únicamente existe la legislación de la Unión en aquellos casos en los que un trabajador se reincorpora a su puesto tras un permiso parental"; y, en lo referente a la igualdad de género, "el pilar centra por primera vez la atención en garantizar la igualdad de acceso de hombres y mujeres en materia de disposiciones sobre permisos especiales. Debería promoverse un uso equilibrado de este tipo de disposiciones por parte de hombres y mujeres, por ejemplo, ajustando el nivel de remuneración, o las condiciones relativas a la flexibilidad y a su carácter intransferible". Vid. el Documento de trabajo de los servicios de la Comisión que acompaña a la Comunicación de la Comisión al Parlamento Europeo, al Consejo, al Comité Económico y Social Europeo y al Comité Europeo de las Regiones "Establecimiento de un pilar europeo de derechos sociales".

94 Tal y como se pone de manifiesto en la propia Recomendación (UE) 2017/761, el Pilar Europeo de Derechos Sociales "Reafirma algunos de los derechos del acervo de la Unión y añade nuevos principios que abordan los desafíos derivados de los cambios económicos, tecnológicos y sociales" (considerando 14). Vid. el análisis detallado de los nuevos elementos que aporta el Pilar Europeo de Derechos Sociales al acervo europeo existente que se realiza en el Documento de trabajo de los servicios de la Comisión que acompaña a la Comunicación de la Comisión al Parlamento Europeo, al Consejo, al Comité Económico y Social Europeo y al Comité Europeo de las Regiones "Establecimiento de un pilar europeo de derechos sociales". Vid. también TORRECILLA, Eduardo Rojo. La construcción del Pilar Europeo de Derechos Sociales. De la Propuesta Juncker (9.9.2015) a la Recomendación de la Comisión Europea (26.4.2017). ¿Más Europa social o reordenación del marco normativo vigente? Revista Galega de Dereito Social, Santiago de Compostela, n. 3, 2017, p. 63-73. 
ción coherente de los principios y derechos sociales existentes en la Unión ${ }^{95}$. Eso sí, el Pilar requerirá de un fuerte compromiso político tanto en sede de las instituciones de la Unión Europea como por parte de los Estados miembros, en las decisiones que se adopten en materia de política económica y social ${ }^{96}$. En cualquier caso, su adopción ha supuesto la reafirmación y el reconocimiento de los valores del modelo social europeo, así como de su lugar central en el proyecto de integración europea ${ }^{97}$, por lo que no puede negarse su relevancia, en cuanto reafirma el compromiso de la Unión Europea con el contenido social del proyecto de integración europea. Además, "al situar a la convergencia social en los procedimientos e instrumentos de gobernanza de la Unión Económica y Monetaria equilibra los objetivos económicos y sociales y permite la consideración de la convergencia y de la Justicia Social como un factor positivo también desde la perspectiva económica del desarrollo de las potenciales del Mercado y de la Moneda"98.

Por otra parte, el Pilar también puede considerarse, desde una segunda vertiente, como programa de acción de las instituciones de la Unión Europea y de los Estados miembros $^{99}$. Desde esta perspectiva, como afirman José Luis Monereo y Juan Antonio Fernández, "puede llegar a servir de palanca de promoción del acervo social existente en la Unión y su aplicación plena y adecuada"100. Y ello es relevante y puede suponer una gran oportunidad para el fortalecimiento de la dimensión social de la Unión Europea, si sus previsiones acaban implementándose y materializándose a través de medidas y normas concretas, como sería deseable. Desde esta perspectiva, en el ámbito de la Unión Europea, el Pilar debería servir para inspirar la acción de las instituciones y para relanzar el proceso de convergencia dentro de la Unión económica y monetaria, sirviendo de orientación para futuras acciones y normas para la zona del euro. Para

95 PÉREZ, José Luis Monereo; BERNAT, Juan Antonio Fernández. El pilar europeo de los derechos sociales: un mecanismo insuficiente para garantizar la dimensión social. Diario La Ley, Madrid, n. 9001, de 15 de junio de 2017, p. 18.

96 Vid. QUINTANA, Margarita Isabel Ramos. El "momento cumbre" del pilar europeo de derechos sociales. Trabajo y Derecho, Madrid, n. 37, 2018, p. 4.

97 ALONSO, Alejandro Cercas. El Pilar Europeo de Derechos Sociales. En: NASARRE, Eugenio; LUZÁRRAGA, Francisco Aldecoa; SOLSONA, Miguel Ángel Benedicto (coords.). Europa como tarea a los sesenta años de los Tratados de Roma y a los setenta del Congreso de Europa de La Haya. Madrid: Marcial Pons, 2018, p. 257.

98 ALONSO, Alejandro Cercas. El Pilar Europeo de Derechos Sociales. En: NASARRE, Eugenio; LUZÁRRAGA, Francisco Aldecoa; SOLSONA, Miguel Ángel Benedicto (coords.). Europa como tarea a los sesenta años de los Tratados de Roma y a los setenta del Congreso de Europa de La Haya. Madrid: Marcial Pons, 2018, p. 263.

99 QUINTANA, Margarita Isabel Ramos. El "momento cumbre" del pilar europeo de derechos sociales. Trabajo y Derecho, Madrid, n. 37, 2018, p. 5.

100 PÉREZ, José Luis Monereo; BERNAT, Juan Antonio Fernández. El pilar europeo de los derechos sociales: un mecanismo insuficiente para garantizar la dimensión social. Diario La Ley, Madrid, n. 9001, de 15 de junio de 2017, p. 18. 
Francisco Pérez, probablemente la mejor aportación del Pilar es que prepara el escenario para las primeras iniciativas para dotarlo de contenido material ${ }^{101}$.

Por último, no puede negarse el valor añadido que tiene el Pilar al tratarse de un instrumento supranacional. Si bien las funciones típicas del Estado del bienestar se siguen acometiendo con carácter principal a nivel de los Estados y las prácticas son heterogéneas, ${ }^{102}$ la adopción de este instrumento a nivel supranacional tiene un gran valor que, como advierte Alejandro Cercas, "se encuentra sobre todo en la calidad, en la coherencia, en las sinergias, en la metodología, o en el aprendizaje que opera entre los Estados miembros y en la sociedad civil europea"103.

En definitiva, "el pilar ha de contribuir a modernizar, ampliar y profundizar e intensificar los derechos sociales, tanto en el trabajo como en la sociedad, facilitando su asimilación real y fomentando prácticas que puedan ser beneficiosas desde el punto de vista de los individuos, de las empresas y de la sociedad"104.

\subsection{Principales limitaciones}

A pesar del avance que supone la aprobación del Pilar Europeo de Derechos Sociales, no pueden negarse las limitaciones que presenta este instrumento en aras a su efectividad. Sin duda, la limitación más importante es la ausencia de fuerza jurídica vinculante. El Pilar se formula jurídicamente, en un inicio, como una Recomendación de la Comisión en abril de 2017 y, posteriormente, se proclama a través de una declaración interinstitucional del Parlamento Europeo, el Consejo y la Comisión, en noviembre de $2017^{105}$. Ambos instrumentos carecen de valor jurídico vinculante, por lo que, lejos de imponer obligaciones de necesario cumplimiento, se limitan a establecer previsiones de cumplimiento facultativo, sin que su incumplimiento lleve aparejada consecuencia jurídica alguna, lo que ha suscitado importantes críticas en la doctrina ${ }^{106}$. Partimos, por

101 AMORÓS, Francisco Pérez. Los retos laborales de la UE en su $60^{\circ}$ aniversario: el Pilar Europeo de Derechos Sociales (1). Trabajo y Derecho, Madrid, n. 35, 2017, p. 11.

102 FORNS I FERNÁNDEZ, Maria Victòria. Los servicios sociales locales como garantes del Estado del Bienestar en el Estado Español: análisis del régime jurídico de la atención a la persona en Cataluña. Revista de Direito Econômico e Socioambiental, Curitiba, v. 9, n. 3, p. 3-54, set./dez. 2018.

103 ALONSO, Alejandro Cercas. El Pilar Europeo de Derechos Sociales. En: NASARRE, Eugenio; LUZÁRRAGA, Francisco Aldecoa; SOLSONA, Miguel Ángel Benedicto (coords.). Europa como tarea a los sesenta años de los Tratados de Roma y a los setenta del Congreso de Europa de La Haya. Madrid: Marcial Pons, 2018, p. 259.

104 Comunicación de la Comisión al Parlamento Europeo, a Consejo, al Comité Económico y Social Europeo y al Comité de las Regiones "Apertura de una consulta sobre un pilar europeo de derechos sociales", p. 8 [COM (2016) 127 final, Estrasburgo, 8 de marzo de 2016].

105 Respecto a la naturaleza jurídica del Pilar Europeo de Derechos Sociales cabe destacar que, inicialmente, la Comisión no se decantaba por ninguna opción en particular (vinculante o no). Vid. PÉREZ, José Luis Monereo; BERNAT, Juan Antonio Fernández. El pilar europeo de los derechos sociales: un mecanismo insuficiente para garantizar la dimensión social. Diario La Ley, Madrid, n. 9001, de 15 de junio de 2017, p. 7-8.

106 Vid., por ejemplo, ALONSO, Alejandro Cercas. El Pilar Europeo de Derechos Sociales. En: NASARRE, Eugenio; LUZÁRRAGA, Francisco Aldecoa; SOLSONA, Miguel Ángel Benedicto (coords.). Europa como tarea a los 
tanto, de un instrumento jurídico débil y frágil ${ }^{107}$, susceptible de ser calificado como de soft law, cuya efectividad dependerá, en gran medida, de la seriedad y del rigor con que se aborden los asuntos sociales en el entramado institucional de la Unión Europea ${ }^{108}$ y en los propios Estados miembros. En cualquier caso y a salvo de lo que pueda deparar el futuro, es dudoso que esta actual configuración, sin valor jurídico vinculante, pueda resultar suficiente para fortalecer y reforzar la dimensión social de la Unión Europea ${ }^{109}$. Existe, por tanto, el riesgo de que quede en una propuesta vacía de contenido ${ }^{110}$.

Dada la naturaleza jurídica del pilar, estos principios y derechos no son directamente aplicables y será necesario que se traduzcan en acciones específicas o normas, al correspondiente nivel ${ }^{111}$, que son las que acabarán determinando su eficacia ${ }^{112}$. En cuanto a quién corresponde el cumplimiento de sus objetivos, "constituye un com-

sesenta años de los Tratados de Roma y a los setenta del Congreso de Europa de La Haya. Madrid: Marcial Pons, 2018, p. 262; En esta misma línea, PÉREZ, José Luis Monereo; BERNAT, Juan Antonio Fernández. El pilar europeo de los derechos sociales: un mecanismo insuficiente para garantizar la dimensión social. Diario La Ley, Madrid, n. 9001, de 15 de junio de 2017, p. 18, advierten que"frente a los desafíos que vive Europa y en un momento de cierta recuperación económica lo más oportuno hubiera sido iniciar un debate de mayor alcance para llegar a adoptar un mecanismo más reforzado en términos jurídicos o directamente proceder a conseguir una constitucionalización social fuerte de los derechos. Poco se podrá hacer a través del mecanismo del pilar europeo de derechos sociales porque a día de hoy la constitución económica de la que se habló más arriba se impone de manera determinante al constitucionalismo social. Tal y como está configurado dicho instrumento, resulta insuficiente para proteger o tutelar los derechos sociales fundamentales".

107 QUINTANA, Margarita Isabel Ramos. El "momento cumbre" del pilar europeo de derechos sociales. Trabajo y Derecho, Madrid, n. 37, 2018, p. 5.

108 QUINTANA, Margarita Isabel Ramos. El pilar europeo de derechos sociales: ¿nos ponemos serios? Trabajo y Derecho, Madrid, n. 24, 2016, p. 4.

109 En este mismo sentido, CORUJO, Borja Suárez. El Pilar Europeo de Derechos Sociales ¿El anhelado punto de inflexión? Agenda Pública, El Periódico, 19 de noviembre de 2017. También ALONSO, Alejandro Cercas. El Pilar Europeo de Derechos Sociales. En: NASARRE, Eugenio; LUZÁRRAGA, Francisco Aldecoa; SOLSONA, Miguel Ángel Benedicto (coords.). Europa como tarea a los sesenta años de los Tratados de Roma y a los setenta del Congreso de Europa de La Haya. Madrid: Marcial Pons, 2018, p. 262, advierte que "El instrumento elegido, una proclamación de naturaleza política, y la opción de la Comisión por sus facultades de orientación, frente al uso de iniciativas legislativas o nuevos instrumentos financieros, suscitan en muchos el temor a que estemos en vísperas de nuevas promesas incumplidas, que no resuelvan los problemas y alimenten las corrientes deslegitimadoras".

110 CORUJO, Borja Suárez. El Pilar Europeo de Derechos Sociales ¿El anhelado punto de inflexión? Agenda Pública, El Periódico, 19 de noviembre de 2017. También ALONSO, Alejandro Cercas. El Pilar Europeo de Derechos Sociales. En: NASARRE, Eugenio; LUZÁRRAGA, Francisco Aldecoa; SOLSONA, Miguel Ángel Benedicto (coords.). Europa como tarea a los sesenta años de los Tratados de Roma y a los setenta del Congreso de Europa de La Haya. Madrid: Marcial Pons, 2018, p. 262.

111 Así se pone de manifiesto en el Documento de trabajo de los servicios de la Comisión que acompaña a la Comunicación de la Comisión al Parlamento Europeo, al Consejo, al Comité Económico y Social Europeo y al Comité Europeo de las Regiones "Establecimiento de un pilar europeo de derechos sociales".

112 Es interesante la lectura del Documento de trabajo de los servicios de la Comisión que acompaña a la Comunicación de la Comisión al Parlamento Europeo, al Consejo, al Comité Económico y Social Europeo y al Comité Europeo de las Regiones "Establecimiento de un pilar europeo de derechos sociales". En él, para cada uno de los principios recogidos en el Pilar, se aborda cómo los Estados miembros y los interlocutores sociales, que tienen la responsabilidad principal de hacer que los principios y derechos sociales sean operativos en la práctica, podrían aplicar de forma efectiva cada principio o derecho. Por otra parte, también describe cómo podrían contribuir las actuaciones de la Unión a la aplicación del pilar. 
promiso y una responsabilidad compartidos por la Unión, los Estados miembros y los interlocutores sociales ${ }^{113 " 114}$, que "actúan en consonancia con la distribución de las competencias establecidas por los Tratados de la Unión y teniendo en cuenta los principios de subsidiariedad y proporcionalidad, finanzas públicas sólidas y respeto por la autonomía de los interlocutores sociales"115. Ahora bien, son los Estados miembros y los interlocutores sociales quienes tienen la responsabilidad principal de hacer que los principios y derechos sociales sean operativos en la práctica y quienes podrían aplicar de forma efectiva cada principio o derecho. Tal y como se destaca en la Recomendación de la Comisión sobre el Pilar Europeo de Derechos Sociales, "El diálogo social desempeña un papel fundamental en el refuerzo de los derechos sociales y del crecimiento sostenible e inclusivo"116 y "Los interlocutores sociales a todos los niveles desempeñan un papel crucial en el desarrollo y la aplicación del pilar europeo de derechos sociales, de conformidad con su autonomía y su derecho a la acción colectiva"117. Todo ello sin olvidar que las actuaciones de la Unión también pueden contribuir de forma decisiva a la aplicación del Pilar.

En otro orden de cosas, no pueden obviarse el coste que conlleva una aplicación efectiva del Pilar Europeo de Derechos Sociales y las limitaciones económicas existentes para garantizar su cumplimiento, tanto en el seno de la Unión Europea ${ }^{118}$ como en el de los Estados miembros. Al respecto, debe tenerse presente que

113 En el Documento de trabajo de los servicios de la Comisión que acompaña a la Comunicación de la Comisión al Parlamento Europeo, al Consejo, al Comité Económico y Social Europeo y al Comité Europeo de las Regiones "Establecimiento de un pilar europeo de derechos sociales", se afirma que "La implicación de los interlocutores sociales también es fundamental para la obtención de los derechos sociales. La promoción del diálogo entre los interlocutores sociales se consagra como objetivo común de la Unión y los Estados miembros en el artículo 151 del TFUE. A escala de la Unión, dentro de los ámbitos políticos a los que se refiere el artículo 153 del TFUE, debe consultarse a los interlocutores sociales con arreglo al artículo 154 del TFUE y pedir la aplicación de sus acuerdos a escala de la Unión de conformidad con el artículo 155. Los interlocutores sociales pueden respaldar la aplicación del pilar por medio de la negociación colectiva en el contexto nacional o mediante la recopilación y el intercambio de buenas prácticas en toda Europa".

114 Considerando $17^{\circ}$ de la Recomendación (UE) 2017/761 de la Comisión.

115 Documento de trabajo de los servicios de la Comisión que acompaña a la Comunicación de la Comisión al Parlamento Europeo, al Consejo, al Comité Económico y Social Europeo y al Comité Europeo de las Regiones "Establecimiento de un pilar europeo de derechos sociales".

116 Considerando $20^{\circ}$ de la Recomendación (UE) 2017/761 de la Comisión. También en el Documento de trabajo de los servicios de la Comisión que acompaña a la Comunicación de la Comisión al Parlamento Europeo, al Consejo, al Comité Económico y Social Europeo y al Comité Europeo de las Regiones "Establecimiento de un pilar europeo de derechos sociales", se pone de relieve que "es fundamental el diálogo civil tanto en el contexto nacional como a nivel de la Unión para ampliar la participación en la elaboración de políticas y movilizar más a los agentes sociales para que contribuyan a materializar los principios y derechos del pilar. Un diálogo civil en el que participen las organizaciones de la sociedad civil permite que estén representados variados intereses de las partes interesadas cívicas y refuerza la transparencia, la asunción de responsabilidades y la legitimidad de las decisiones públicas".

117 Considerando $20^{\circ}$ de la Recomendación (UE) 2017/761 de la Comisión.

118 En cuanto a la financiación en el ámbito de la Unión Europea, debe tenerse en cuenta la aplicación de sus Fondos para financiar la aplicación del Pilar Europeo de Derechos Sociales. Los Fondos Estructurales y 
El pilar debería aplicarse con arreglo a los recursos disponibles y dentro de los límites de una gestión presupuestaria sólida, así como de las obligaciones del Tratado que rigen las finanzas públicas. En concreto, el establecimiento del pilar no afecta a la facultad reconocida a los Estados miembros de definir los principios fundamentales de sus sistemas de seguridad social ni debe afectar de modo sensible al equilibrio financiero de este.

Otra limitación a tener en cuenta es que el Pilar no supone la formulación de más derechos o de nuevos derechos en el ámbito social, ni en el ámbito europeo ni en el ámbito nacional de cada Estado, ya que debe aplicarse dentro de las competencias que corresponden a la Unión Europea ${ }^{119}$. En ningún caso implica una ampliación de las competencias de la Unión definidas por los Tratados, por lo que debe aplicarse dentro de los límites de dichas competencias ${ }^{120}$. Por lo tanto, no supone una ampliación de los derechos. De esta forma, los principios y los derechos en él recogidos deben aplicarse, tanto a nivel de la Unión como de los Estados miembros, dentro de los márgenes de sus respectivas competencias y de conformidad con el principio de subsidiariedad ${ }^{121}$. Ahora bien, no se impide -aunque tampoco se obliga- que los Estados miembros -o sus interlocutores sociales- puedan establecer normas sociales más ambiciosas ${ }^{122}$. Efectivamente, a nivel de los Estados miembros, el Pilar respeta la diversidad de culturas y tradiciones, así como la identidad nacional de los Estados miembros y la organización de sus poderes públicos a escala nacional, regional y local. En particular, su establecimiento "no afecta al derecho de los Estados miembros de definir los principios fundamentales de sus sistemas de seguridad social y no debe afectar al equilibrio financiero de este"123.

de Inversión Europeos respaldarán su aplicación del pilar europeo de derechos sociales. En concreto, el Fondo Social Europeo, así como otras iniciativas fundamentales de cohesión social, como la Iniciativa de Empleo Juvenil, el Fondo Europeo de Adaptación a la Globalización y el Fondo de Ayuda Europea para las Personas Más Desfavorecidas, tendrán un papel crucial en el seguimiento del pilar. Vid. el Documento de trabajo de los servicios de la Comisión que acompaña a la Comunicación de la Comisión al Parlamento Europeo, al Consejo, al Comité Económico y Social Europeo y al Comité Europeo de las Regiones “Establecimiento de un pilar europeo de derechos sociales".

119 TORRECILLA, Eduardo Rojo. La construcción del Pilar Europeo de Derechos Sociales. De la Propuesta Juncker (9.9.2015) a la Recomendación de la Comisión Europea (26.4.2017). ¿ Más Europa social o reordenación del marco normativo vigente? Revista Galega de Dereito Social, Santiago de Compostela, n. 3, 2017, p. 62.

120 Vid. el Considerando $18^{\circ}$ de la Recomendación (UE) 2017/761 de la Comisión.

121 Vid. el Considerando $17^{\circ}$ de la Recomendación (UE) 2017/761 de la Comisión.

122 Así se recoge de forma expresa en el Considerando 16 de la Recomendación (UE) 2017/761 de la Comisión.

${ }^{123}$ Considerando $19^{\circ}$ de la Recomendación (UE) 2017/761 de la Comisión. Como pone de manifiesto TORRECILLA, Eduardo Rojo. La construcción del Pilar Europeo de Derechos Sociales. De la Propuesta Juncker (9.9.2015) a la Recomendación de la Comisión Europea (26.4.2017). ¿Más Europa social o reordenación del marco normativo vigente? Revista Galega de Dereito Social, Santiago de Compostela, n. 3, 2017, p. 62-63, esta afirmación recogida en la Recomendación "demuestra las dificultades para avanzar en un auténtico sistema europeo de Seguridad Social". 
A la vista de lo expuesto, queda claro que el Pilar no supone la introducción de más derechos, sino la reafirmación de los existentes, sin perjuicio de algunas mejoras introducidas ${ }^{124}$. En opinión de Francisco Pérez ${ }^{125}$, a la luz de su contenido y sus limitaciones,

[...] no cabe una valoración totalmente positiva aunque haya creado esperanzas: las novedades reales son más bien escasas, la terminología excesivamente declarativa, y sin precisiones suficientes sobre el formato legal del futuro pilar. De momento más bien parece que -como puntual y recientemente se ha escrito- el pilar europeo ha despertado "expectativas", pero también generado "desconfianza" porque está "basado en principios ya tantas veces manoseados por la burocracia de la Unión..." y, falto de "concreción política y normativa...".

\section{ACCIONES POSTERIORES A NIVEL EUROPEO TRAS LA APROBA- CIÓN DEL PILAR EUROPEO DE DERECHOS SOCIALES}

Como hemos señalado, el cumplimiento de los objetivos del Pilar Europeo de Derechos Sociales constituye un compromiso y una responsabilidad compartidos por la Unión Europea, los Estados miembros y los interlocutores sociales. Desde la perspectiva de la Unión, a la aprobación del Pilar ha seguido la adopción por parte de la Comisión de las primeras iniciativas concretas. Si bien la mayoría de los instrumentos para su implementación están en manos de los Estados miembros, así como de los interlocutores sociales y de la sociedad civil, las instituciones de la Unión -y, en particular, la Comisión Europea- pueden contribuir a establecer el marco y a marcar el rumbo para el futuro. Una vez adoptado el Pilar, la Comisión ha presentado ya una serie de iniciativas legislativas y no legislativas relacionadas con la conciliación de la vida familiar y la vida profesional, la información de los trabajadores, el acceso a la protección social y el tiempo de trabajo.

En primer lugar, en materia de conciliación de la vida familiar y laboral, cabe mencionar la Propuesta de Directiva del Parlamento Europeo y del Consejo, relativa a la conciliación de la vida familiar y la vida profesional de los progenitores y los cuidadores, y por la que se deroga la Directiva 2010/18/UE del Consejo ${ }^{126}$, destinada a mejorar las condiciones para que los progenitores y los cuidadores que trabajan concilien la vida familiar y la vida profesional.

En segundo lugar, se han puesto en marcha por parte de la Comisión dos consultas con los interlocutores sociales, que reflejan la importancia de la contribución

\footnotetext{
124 Vid. supra el epígrafe 3.5 de este trabajo.

125 AMORÓS, Francisco Pérez. Los retos laborales de la UE en su $60^{\circ}$ aniversario: el Pilar Europeo de Derechos Sociales (1). Trabajo y Derecho, Madrid, n. 35, 2017, p. 6.

126 Propuesta de Directiva del Parlamento Europeo y del Consejo relativa a la conciliación de la vida familiar y la vida profesional de los progenitores y los cuidadores, y por la que se deroga la Directiva 2010/18/UE del Consejo. COM (2017) 253 final, Bruselas, 26 de abril de 2017.
} 
de estos para hacer realidad el Pilar. La primera ha versado sobre la modernización de las normas sobre los contratos de trabajo y tiene como objeto iniciar un debate sobre las garantías mínimas que debe tener todo trabajador, con el fin de proponer una revisión de la Directiva 91/533/CEE, relativa a la obligación del empresario de informar al trabajador acerca de las condiciones aplicables al contrato de trabajo o a la relación laboral. Con posterioridad a esta consulta, efectivamente, se ha presentado una Propuesta de Directiva del Parlamento Europeo y del Consejo relativa a unas condiciones laborales transparentes y previsibles en la Unión Europea ${ }^{127}$. La segunda consulta se ha centrado en el acceso a la protección social, con el fin de definir las posibles nuevas normas en este ámbito y abordar los retos del acceso a la protección social para las personas en cualquier situación de empleo ${ }^{128}$.

En tercer lugar, se ha adoptado una Comunicación interpretativa sobre la Directiva 2003/88/CE del Parlamento Europeo y del Consejo, relativa a determinados aspectos de la ordenación del tiempo de trabajo ${ }^{129}$, que ofrece orientación sobre cómo interpretar varios aspectos de dicha Directiva en consonancia con un volumen creciente de jurisprudencia y así ayudar a los Estados miembros a aplicar el acervo correctamente y a evitar nuevas infracciones.

Por último, la Comisión también ha establecido unos indicadores sociales de seguimiento de la tendencia y los resultados en los Estados miembros en doce ámbitos materiales sociales en los últimos tiempos ${ }^{130}$. La finalidad no es otra que la de evaluar y supervisar su aplicación.

Se advierten, pues, algunas líneas de avance en la implementación del Pilar Europeo de Derechos Sociales en el seno de la Unión Europea. Ahora bien, como pone de manifiesto Francisco Pérez, en relación con las iniciativas adoptadas por la Comisión, "los temas objeto de consideración son muy importantes, pero se aprecian dos limitaciones, faltan otros, y las consideraciones sobre los que se incluyen, son, en muchos casos, generalistas"131.

\footnotetext{
127 Propuesta de Directiva del Parlamento Europeo y del Consejo relativa a unas condiciones laborales transparentes y previsibles en la Unión Europea. COM (2017) 797 final, Bruselas, 21 de diciembre de 2017.

${ }_{128}$ Del 26 de abril al 23 de junio de 2017, los interlocutores sociales pudieron exponer sus puntos de vista sobre ambas cuestiones. Del 21 de septiembre al 3 de noviembre de 2017 tuvo lugar una segunda fase, sobre la modernización de las normas relativas a los contratos de trabajo. El 20 de noviembre de 2017 comenzó la segunda ronda de consultas sobre el acceso a la protección social, que se basa en los resultados de la primera. Paralelamente, la Comisión inició una consulta pública para recabar los puntos de vista de las partes interesadas clave, como los representantes de los autónomos, de la sociedad civil y de los proveedores de protección social.

129 Diario Oficial de la Unión Europea, C 165/1, de 24 de mayo de 2017.

130 Pueden consultarse estos indicadores en: <https://composite-indicators.jrc.ec.europa.eu/social-scoreboard/> Fecha de la última consulta: 21 sep. 2018.

131 AMORÓS, Francisco Pérez. Los retos laborales de la UE en su $60^{\circ}$ aniversario: el Pilar Europeo de Derechos Sociales (1). Trabajo y Derecho, Madrid, n. 35, 2017, p. 12.
} 


\section{CONSIDERACIONES FINALES}

Como hemos tenido ocasión de poner de manifiesto a lo largo de este trabajo, la aprobación del Pilar Europeo de Derechos Sociales en el seno de la Unión Europea merece una valoración positiva. Se trata, sin duda, de una iniciativa que debe aplaudirse por haber puesto sobre la mesa la necesidad de reforzar la dimensión social en el proyecto de integración europea, tras los graves efectos de la crisis económica y de las políticas de austeridad llevadas a cabo en el seno de la Unión Europea para frenarla, en términos de recortes y flexibilización importante de los derechos sociales. ${ }^{132} \mathrm{En}$ un contexto económico más favorable, una iniciativa como la adopción del Pilar, que recoge un programa de principios y derechos sociales básicos para los ciudadanos que pretende dar respuesta a los principales desafíos en materia laboral y social a que se enfrenta la Unión, debe ser bienvenida, por cuanto reafirma la dimensión social de la Unión Europea y su lugar central en el proyecto europeo.

Sin embargo, la actual configuración del Pilar Europeo de Derecho Sociales (una mera Recomendación de la Comisión sin eficacia jurídica vinculante y una declaración interinstitucional sin valor jurídico) parece insuficiente para fortalecer de forma eficaz la dimensión social de la Unión Europea, por lo que no puede dejar de destacarse la debilidad intrínseca que va ínsita a su naturaleza jurídica y realizarse una crítica en este sentido, por no haberse ido más allá. Todo ello sin perjuicio de que el Pilar pueda acabar implementándose y materializándose a través de medidas normativas y, desde esta perspectiva, actuar como motor para el impulso del acervo social de la Unión Europea, si realmente existe voluntad política y compromiso en este sentido a todos los niveles (Unión Europea, Estados miembros e interlocutores sociales). Sería deseable que así fuera y efectivamente se dotase de contenido material y sirviera para inspirar la acción de las instituciones y para relanzar el proceso de convergencia dentro de la Unión económica y monetaria. Para ello es imprescindible, además de un fuerte apoyo presupuestario, un firme compromiso y voluntad política.

Por otra parte, no puede olvidarse que, aunque el Pilar no amplía las competencias de la Unión Europea y tampoco contiene nuevos derechos sociales, ni en el ámbito europeo ni en el ámbito nacional, reafirma los existentes y, en algunos ámbitos (por ejemplo, en materia de equilibro entre la vida profesional y la familiar), introduce algunas mejoras interpretativas que deben valorarse positivamente. Por ello, no puede minusvalorarse su relevancia en este sentido, aunque con las limitaciones ínsitas a su falta de valor jurídico vinculante.

132 Sobre tales efectos en España, ver: FORNS I FERNÁNDEZ, Maria Victòria. El sistema organizativo y competencial de los servicios sociales locales de la post-crisis en el Estado Español. El caso de Catalunya. A\&C - Revista de Direito Administrativo \& Constitucional, Belo Horizonte, ano 18, n. 74, p. 25-66, out./ dez. 2018. 
En definitiva, la construcción de la dimensión social europea tiene todavía muchos retos pendientes. Son muchos los desafíos a que debe darse respuesta y muchas las necesidades que se plantean. De ahí que sea imprescindible un claro compromiso de la Unión Europea -y también de los Estados miembros- y una reafirmación del contenido social del proyecto de integración europea. Desde esta perspectiva, es muy positivo que se haya proclamado el Pilar Europeo de Derechos Sociales. Ahora bien, dadas las limitaciones que presenta este instrumento, no podemos ocultar nuestro escepticismo en torno a su utilidad efectiva como instrumento conducente a un fortalecimiento real de la dimensión social de la Unión Europea que redunde en un mayor bienestar social de los ciudadanos. Si esta iniciativa realmente llegará a cumplir este cometido y supondrá un avance en el ámbito social, o, por el contrario, quedará en una propuesta vacía de contenido, en una simple operación de "maquillaje", sin cambios efectivos, es algo que solo el tiempo nos dirá. Esperemos que no quede relegada en el olvido y pueda lograrse una implementación efectiva de sus postulados, a través de la adopción de medidas concretas, efectivas y eficaces, y conseguirse así una renovación y fortalecimiento real de la dimensión social de la Unión. De ello depende la consolidación de una auténtica Europa social que, además de a los objetivos de integración económica, también atienda a demandas y objetivos sociales, dando lugar a mejores derechos sociales, superando las tesiones y situando ambos objetivos -económicos y sociales- al mismo nivel. En todo caso, como señala Francisco Pérez, "es de esperar y desear el buen fin del pilar, su fracaso no sería una -otra más- ocasión pérdida cualquiera después de haberlo presentado con la solemnidad institucional y pretensiones que se ha hecho"133.

\section{REFERENCIAS}

ALONSO, Alejandro Cercas. El Pilar Europeo de Derechos Sociales. En: NASARRE, Eugenio; LUZÁRRAGA, Francisco Aldecoa; SOLSONA, Miguel Ángel Benedicto (coords.). Europa como tarea a los sesenta años de los Tratados de Roma y a los setenta del Congreso de Europa de La Haya. Madrid: Marcial Pons, 2018.

AMORÓS, Francisco Pérez. Los retos laborales de la UE en su $60^{\circ}$ aniversario: el Pilar Europeo de Derechos Sociales (1). Trabajo y Derecho, Madrid, n. 35, 2017.

BISCHOFF, Gabrielle. El modelo social europeo y los derechos de los trabajadores: ¿por qué necesitamos un pilar europeo de derechos sociales? Temas para el debate, Madrid, n. 268, 2017.

BROTO, José María Miranda. El derecho social de la Unión Europea en la encrucijada: entre la parálisis legislativa y el impulso judicial. Revista del Ministerio de Empleo y Seguridad Social, Madrid, n. 127, 2017.

133 AMORÓS, Francisco Pérez. Los retos laborales de la UE en su 60 aniversario: el Pilar Europeo de Derechos Sociales (1). Trabajo y Derecho, Madrid, n. 35, 2017, p. 
CASADO CASADO, Lucía. Crisis económica y protección del medio ambiente. El impacto de la crisis sobre el Derecho ambiental en España. Revista de Direito Econômico e Socioambiental, Curitiba, v. 9, n. 1, p. 18-63, jan./abr. 2018.

CORUJO, Borja Suárez. El Pilar Europeo de Derechos Sociales ¿El anhelado punto de inflexión? Agenda Pública, El Periódico, 19 de noviembre de 2017.

CORUJO, Borja Suaréz. Las personas con discapacidad en el Pilar Europeo de Derechos Sociales. En: RODRÍGUEZ, Erick Fernando Aristizábal (coord.). Las incapacidades laborales y la Seguridad Social en una sociedad en transformación: I Congreso Internacional y XIV Congreso Nacional de la Asociación Española de Salud y Seguridad Social. Murcia: Ediciones Laborum, 2017.

FERNANDES, Sofia; MASLAUSKAITE, Kristina. Une dimension sociale pour I'UEM: pourquoi et comment? Policy Paper, París, n. 98, 2013.

FORNS I FERNÁNDEZ, Maria Victòria. El sistema organizativo y competencial de los servicios sociales locales de la post-crisis en el Estado Español. El caso de Catalunya. A\&C - Revista de Direito Administrativo \& Constitucional, Belo Horizonte, ano 18, n. 74, p. 25-66, out./ dez. 2018.

FORNS I FERNÁNDEZ, Maria Victòria. Los servicios sociales locales como garantes del Estado del Bienestar en el Estado Español: análisis del régime jurídico de la atención a la persona en Cataluña. Revista de Direito Econômico e Socioambiental, Curitiba, v. 9, n. 3, p. 3-54, set./dez. 2018. GALLARDO, Alfredo Romero. La discapacidad y el nuevo Pilar Europeo de Derechos Sociales. Siglo Cero, Salamanca, v. 49 (2), n. 266, 2018.

GARDINI, Gianluca. Crisis económica y protección de los derechos sociales en Europa. Reflexiones desde el ordenamiento italiano. Revista de Estudios de la Administración Local y Autonómica. Nueva Época, Madrid, n. 9, 2018.

GÓMEZ, Marta Ortega. La Unión Europea frente a los retos políticos, económicos y sociales de la crisis de la Eurozona. En: PÉREZ, Jordi Bonet; ESTAPÀ, Jaume Saura (eds.). El Derecho internacional de los derechos humanos en períodos de crisis. Madrid: Marcial Pons, 2013.

GÓMEZ, Marta Ortega. La política social, el empleo y otras normas sociales de la Unión Europea. En: GÓMEZ, Marta (ed.). Las políticas de la Unión Europea en el siglo XXI. Barcelona: Bosch, 2017.

PÉREZ, José Luis Monereo; BERNAT, Juan Antonio Fernández. El pilar europeo de los derechos sociales: un mecanismo insuficiente para garantizar la dimensión social. Diario La Ley, Madrid, n. 9001, de 15 de junio de 2017.

QUINTANA, Margarita Isabel Ramos. El pilar europeo de derechos sociales: ¿nos ponemos serios? Trabajo y Derecho, Madrid, n. 24, 2016.

QUINTANA, Margarita Isabel Ramos. El Pilar Europeo de Derechos Sociales: la nueva dimensión social europea. Revista de Derecho Social, Albacete, n. 77, 2017. 
QUINTANA, Margarita Isabel Ramos. El "momento cumbre" del pilar europeo de derechos sociales. Trabajo y Derecho, Madrid, n. 37, 2018.

SANZ, Rosario Pedrosa. El desarrollo histórico de la Política Social de la Unión Europea y su estado actual. Estudios de Economía aplicada, Valladolid, v. 27-3, 2009.

TORRECILLA, Eduardo Rojo. La construcción de la dimensión social de la Unión Europea: muchos retos pendientes y muchas necesidades a las que responder. Anuario IET de Trabajo y Relaciones Laborales, Barcelona, v. 2, 2014.

TORRECILLA, Eduardo Rojo. La construcción del Pilar Europeo de Derechos Sociales. De la Propuesta Juncker (9.9.2015) a la Recomendación de la Comisión Europea (26.4.2017). ¿Más Europa social o reordenación del marco normativo vigente? Revista Galega de Dereito Social, Santiago de Compostela, n. 3, 2017. 